\title{
The Catch-22 of Countering a Moral Occupational Stigma in Employee-Customer Interactions
}

\author{
Forthcoming in Academy of Management Journal
}

\author{
Sven Mikolon \\ Imperial College London \\ s.mikolon@imperial.ac.uk \\ Office: +44 (0)20 7594-9160 \\ Sascha Alavi \\ Ruhr-University of Bochum \\ sascha.alavi@ruhr-uni-bochum.de \\ Office: +49 (0)234 32-26596
}

Anika Reynders

Independent

anika.reynders@rub.de

Acknowledgments: We are grateful to associate editor Lisa M. Leslie and the reviewers for their feedback and guidance throughout the review process. We would also like to thank Maria Farkas, Glen Kreiner, Yuri Mishina, Jan Ross, Erk Piening, Till Haumann and Pascal Güntürkün for their helpful comments on earlier drafts of this manuscript. We also appreciate the feedback we received from attendants of the Management Department's monthly paper development workshop at Imperial College Business School, for which we had submitted an earlier draft of this manuscript. 


\title{
THE CATCH-22 OF COUNTERING A MORAL OCCUPATIONAL STIGMA IN EMPLOYEE-CUSTOMER INTERACTIONS
}

\begin{abstract}
Past research suggests that individuals in dirty work occupations can manage their self-views so as to derive positive self-definitions that allow them to perform their tasks with less of the burden of stigma. Results from our three studies show that this may not necessarily be the case when they try to manage how occupational outsiders view them. Findings from our studies show that in terms of this external perspective, rather than thwarting the occupational stigma, active stigma management by the stigma bearer can unintentionally reinforce the stigma. Drawing on the expectancy-confirmation framework from the stereotyping literature, we explain the cognitive mechanism that underlies this inadvertent stigma reinforcement in the stigma perceiver and investigate the job performance implications for the stigma bearer. We test our hypotheses across two field studies and one experimental study, involving cross-industry and cross-sectional data, as well as one longitudinal data-set including 128,549 employee-customer transactions. Our results contribute to research on dirty work by revealing that stigma management can be a double-edged sword with unintended negative consequences for the stigmatized worker.
\end{abstract}

\section{Keywords}

Occupational stereotypes; Dirty work; Job performance; Stigma

Occupations can become morally stigmatized when a significant proportion of society views them as involving dubious, sinful, deceptive, or confrontational methods that are deeply connected to the nature of the work (Ashforth \& Kreiner, 1999, 2014; Hughes, 1951). Persons performing such morally tainted occupations - sometimes known as 'dirty workers', e.g., telemarketers, bill collectors, real estate agents, used-car salespeople, investment bankers - find themselves on the receiving end of negative integrity-related stereotypes. These stereotypes not only pose an identity dilemma for these workers (e.g., Ashforth \& Kreiner, 1999), but also jeopardize their performance in tasks that involve interpersonal interactions, such as employeecustomer interactions. A relevant question then arises as to how holders of such dirty work occupations can effectively mitigate their stigma to thwart a potential negative impact on job performance in interactions with customers. 
Answering this question based on current research on dirty work research proves surprisingly difficult. This stream of research has presented ample empirical evidence that dirty workers are remarkably creative in edifying the meaning of their work so that they can develop positive self-views, despite of a publicly stigmatized image (e.g., Ashforth, Kreiner, Clark, \& Fugate, 2007; Dick, 2005; Tracy \& Scott, 2006). In this way, then, gaining social approval even in the face of widespread social disapproval is the central dilemma for those in dirty work occupations (Ashforth \& Kreiner, 1999). Stigmatized workers employ tactics to counter the negative effects of stigma, which are underpinned by a set of stigma management principles, such as reframing, recalibrating, or refocusing (Ashforth \& Kreiner, 1999, 2014), which have found broad empirical support across a variety of occupations (e.g., Ashforth et al., 2007; Dick, 2005; Slutskaya, Simpson, Hughes, Simpson \& Uygur, 2016; Stacey, 2006; Tracy \& Scott, 2006). For example, to derive positive self-views, many exotic dancers refocus on the income their job provides (Mavin \& Grandy, 2013), and zookeepers may reframe the purpose of their job as protecting biodiversity (Bunderson \& Thompson, 2009).

However, in focusing on how these tactics change dirty workers' self-views, this research has largely sidestepped how they may change others' views of them. The central notion of these empirical findings is that stigma management tactics are by and large effective in protecting the workers' self from negative stereotyping (e.g., Ashforth et al., 2007) - that is, in protecting them from internalizing a negative self-view; what is less clear is how these tactics might function when employed in interpersonal interactions with occupational outsiders. For instance, when a morally stigmatized hedge fund manager claims that her activities help to maintain market efficiency, this claim will likely help to bolster her self-view - but will it also educe approval from others? 
In this paper, we consider two stigma-countering tactics put forth in the dirty work literature - a social comparison tactic and a reframing tactic (Ashforth \& Kreiner, 1999, 2014). We suggest that when morally tainted targets employ these tactics to manage how others view them, they may not necessarily reduce negative consequences of stigma, as might be expected based on extant dirty work research (e.g., Ashforth \& Kreiner, 1999; Ashforth et al., 2007; Dick, 2005; Tracy \& Scott, 2006). Instead, because stigmas tend to act as interpretative lenses through which perceivers come to understand the stigmatized (e.g., Ashforth 2019), individuals attempting to counter their stigma may unwittingly reinforce others' negative reactions (Dovidio, 2001; Kleck, 1969). In order to conceptualize such a stigma-reinforcement mechanism, we draw on the expectancy-confirmation framework in the stereotyping literature (Darley \& Gross, 1983). We propose that when stigmatized actors employ social comparison tactics they may ironically confirm perceivers' negative stereotypical expectancies associated with their stigma and reinforce their initial moral occupational stigma.

We investigate these hypotheses in the context of customer-facing employees. As part of their job description, organizational frontline employees are required to effectively interface with organizational outsiders (Adams, 1976). Therefore, their job performance heavily depends on their target audience's approval (Ahearne, Bhattacharya, \& Gruen, 2005; Chebat \& Kollias, 2000). However, some frontline occupations, such as sales jobs, have become associated with a moral stigma because they are perceived to involve deceptive or intrusive methods (Hartman, 2006; Ingram \& Schwepker, 1993; Baldwin, 1992). Hence, negative stereotypes of immorality such as being greedy and selfish - tend to be attributed to those performing sales jobs (Hartman, 2006; Adkins \& Swan, 1981; Rotter \& Stein, 1971). 
In testing our hypotheses, we apply an iterative approach. We suggest social comparisons and reframing claims as two stigma-countering tactics, previously identified in the stigma management literature (Ashforth \& Kreiner, 1999, 2014) that frontline employees use to counter the stereotypes of immorality associated with their occupational stigma. We test the effectiveness of these stigma-countering tactics across two field studies — one study involving a longitudinal data-set including 128,549 employee-customer transactions and one cross-sectional study spanning multiple industries. In addition, using an experimental study, we extend the findings from the field by revealing that the intensity of the stigma (Kreiner, Ashforth, \& Sluss, 2006) functions as a moderator for the stigma-countering tactics to exert a significant indirect impact on frontline workers' job performance, such that this impact is stronger when the stigma is of high intensity than when it is of low intensity.

The results of this investigation contribute to research on dirty work and stigma management in several ways. The dirty work literature suggests that stigma-countering tactics may be effective, enabling dirty workers to perform their tasks with reduced burden of stigma (Ashforth et al., 2007; Tracy \& Scott, 2006). However, our findings demonstrate that this is not necessarily the case when workers employ these tactics to actively manage how they are viewed in interactions with occupational outsiders. Such stigma-countering efforts can then backfire. Indeed, these findings imply that drawing downward social comparisons, a behavior that seems to be functional for creating self-affirmation based on the current research, can in fact be dysfunctional when aimed at creating approval from occupational outsiders. Our findings are theoretically relevant because they address the central dilemma of dirty work jobs - namely, how can members of dirty work occupations gain social approval despite their stigma, rather than merely gaining self-approval, which previous work has focused on (e.g., Bosmans et al., 2016; 
Hughes et al., 2016). While targets of occupational stigma might be relatively successful in shielding their own self-image against the effects of stigma (e.g., Ashforth et al. 2007; Hamilton, Redman, McMurray, 2019), our findings suggest that it may be far more difficult to prevent others from viewing them through the lens of occupational stigma. Examining the outwardfacing consequences of stigma management can hence yield a fuller understanding of the phenomenon of dirty work.

Furthermore, this understanding takes the effects of stigma management beyond the inward-facing challenges that individuals face, such as developing positive self-definitions (e.g., Ashforth et al., 2007; Hamilton, Redman, McMurray, 2019), to tasks that involve interpersonal interactions within organizations. To the extent that tactics can have the opposite of the intended effects, our findings may open the way to ensuring that stigma-countering is instrumental for frontline employees' performance rather than a constraint on their work outcomes. Accordingly, our theoretical claims about the relative instrumentality of two stigma-countering tactics carry important actionable implications, as the job performance of customer-facing employees has direct bottom-line implications for organizations (Batt, 2002).

\section{MORAL OCCUPATIONAL STIGMA AND STIGMA-COUNTERING Moral Occupational Stigma}

There are two major sources from which employees can acquire a stigma - from their personal and social characteristics, e.g., gender, ethnicity, sexual orientation, or disability, or from their occupation (i.e., dirty work jobs). While the majority of work on stigma management has focused on stigmas stemming from workers' personal and social characteristics (e.g., Ali, Lyons, \& Ryan, 2017; Lyons, Volpone, Wessel, \& Alonso, 2017; Davis, 1961; Johnson, Sitzmann \& Nguyen, 2014; Miller, Rothblum, Felicio, \& Brand, 1995; Singletary \& Hebl, 2009), 
which are external to the work domain (Kreiner \& Mihelcic, 2020), less research has focused on stigmas stemming from workers' occupations.

An occupation can be stigmatized on physical, social, or moral grounds (Ashforth 2019, Hughes, 1951). A moral occupational stigma occurs when an occupation is generally regarded as “dubious" by society (Hughes, 1951). Moral taint represents a symbolic threat to society because it questions established definitions of cleanliness and moral order (Ashforth \& Kreiner, 1999). The application of negative stereotypes - rigid and over-generalized beliefs and expectations (Hilton \& von Hippel, 1996; Hamilton \& Trolier, 1986) associated with the dubious category to its members - is at the core of stigmatization processes (Stangor \& Crandall, 2000). The category stereotypes are then applied to everyone associated with a given category, irrespective of whether they actually possess the stereotypical traits. This process is stigmatization. Accordingly, morally stigmatized occupations are at the receiving end of stereotypes of immorality.

\section{Extant Research on Stigma-Countering}

Workers to whom such noxious characteristics are ascribed often attempt to manage information related to their stigma for the perceiver (for a review see Jones \& King, 2014). A key element of such management are attempts by the stigmatized to counter the ascription of negative stigma-related stereotypes. Such stigma-countering can occur through a variety of countering tactics, which mutatis mutandis, tend to be directed to occupational insiders- and outsiders alike (Ashforth et al., 2007; Ashforth \& Kreiner, 1999). Research on stigma management has identified two classes of stigma-countering tactics with respect to the two archetypical sources of stigma—-workers' personal or social characteristics (Crocker, Major, \& Steele, 1998) and workers' occupations (Ashforth \& Kreiner, 1999, 2014). While these two sets of tactics are both aimed at thwarting the consequences of stigma, they differ structurally 
between occupational and social stigmas (cf. Neel, Neufeld, \& Neuberg, 2013). For example, tactics addressing stigmas originating from the workers' personal or social characteristics are often aimed at achieving an individualistic solution to stigmatization for individual-level challenges such as obtaining hiring recommendations (e.g., Ali, Lyons \& Ryan, 2017; Johnson, Sitzmann \& Nguyen, 2014; Lyons et al., 2017) or reducing interpersonal discrimination (Singletary \& Hebl, 2009; King et al., 2006). That is, they are aimed at achieving a more positive or less negative image for the stigmatized as an individual person.

Unlike tactics for personal or social categories, occupational stigma-countering tactics are often the result of a collective sense-making effort by occupational members to understand how society views them and what is deemed problematic about the work they do (Ashforth \& Kreiner, 1999). Thus, these tactics are often aimed at achieving a solution to stigmatization for the stigmatized collective, such as the occupation, rather than for the stigmatized individual. Seeing these different levels, research has therefore proposed a structurally different set of stigma-countering tactics for occupational stigmas.

In this paper, we focus on the effects of workers' countering of a moral occupational stigma, for which research has suggested a two-process model (Ashforth \& Kreiner, 1999). According to this model, an occupational stigma instigates two processes in the members of targeted occupations: (1) the development of occupational ideologies and (2) the categorization of occupational subgroups and outsiders. Each of these processes engenders a distinct set of stigma-countering tactics (e.g., Ashforth \& Kreiner, 1999; Kreiner \& Mihelcic, 2020), many of which have empirically been confirmed to attenuate the effects of stigma for the bearer (e.g., Ashforth et al., 2007; Dick, 2005; Grandy, 2008; Hughes et al., 2016; Tracy \& Scott, 2006). More specifically, tactics that form on the basis of occupational ideologies are reframing, 
recalibrating, and refocusing. Reframing involves infusing the stigmatized work with positive value; for example, garbage collectors may combat their occupational stigma by claiming to do recycling work (Hamilton, Redman, \& McMurray, 2019), and sex workers may claim that they are offering a therapeutic service (Ashforth \& Kreiner, 1999). Recalibrating involves changing the standards by which the stigmatized components of the occupations are evaluated, so as to make these components to appear less significant (Ashforth \& Kreiner, 1999); one example of recalibrating is firefighters celebrating high-danger tasks as the most valued part of their work when, in fact, most of their daily work is to provide emergency medical services (Tracy \& Scott, 2006). Refocusing sidesteps the stigmatized elements of the occupation, shifting attention to nonstigmatized features of the work; for instance, corrections officers draw satisfaction from their salaries, retirement benefits, and flexible work hours (Tracy \& Scott, 2006).

Another set of tactics is based on the categorization of outsiders to the occupation or to the occupational subgroup, which has also found empirical support (e.g., Ashforth et al., 2007; Bosmans et al., 2016; Hughes et al., 2016). Stigma bearers condemn their condemners and support their supporters, such that stigma bearers condemn unfavorable perceptions of occupational outsiders or emphasize favorable ones (Bosmans et al. 2016). Further, bearers engage in selective social comparisons (Ashforth \& Kreiner 1999) by, for instance, contrasting their group with groups from the same occupation, but from different organizations that are viewed as worse off than their own group (Ashforth et al., 2007). For example, call girls may feel superior to streetwalkers (Asforth \& Kreiner, 1999), and domestic cleaners may disparage cleaners who clean at large companies (Bosmans et al. 2016).

A key finding of the research on tactics to counter occupational stigma is that with these tactics, the stigmatized can effectively preserve a positive self-image in spite of a tainted public 
image (Ashforth \& Kreiner, 2014, 1999; Ashforth et al., 2007). Yet, what is less clear is how these tactics might function when employed in interpersonal interactions with occupational outsiders - that is, how they function to create social affirmation as opposed to self-affirmation.

\section{CONCEPTUAL FRAMEWORK AND HYPOTHESES}

In this investigation, we draw on Ashforth and Kreiner's (1999) aforementioned twoprocess model. This model depicts how workers who are targets of occupational stigma counter the effects of stigma through collectivistic tactics aimed at achieving a solution to stigmatization for their own organizational subgroup. We examine two tactics from this model, which we contextualize to the organizational frontline context: reframing claims and social comparison claims. ${ }^{1}$

\section{Social Comparisons}

According to the two-process model, an occupational stigma instigates the categorization of occupational and subgroup outsiders, which is a prerequisite of social comparisons (Ashforth \& Kreiner, 1999). Indeed, research suggests that individuals working in stigmatized organizations engage in selective social comparisons to shield the self against the taint of the stigma (Ashforth et al., 2007; Bosmans et al., 2016; Hughes et al., 2016). For example, salespeople might state that while others who work for competitors might actually possess the negative stereotypical traits, salespeople in this specific dealership are in fact different. Such direct contrasts are attempts to set one's own specific subgroup apart from the larger stereotyped group of salespeople. The goal is that through selective social comparisons, the own subgroup should stand out in a favorable way and the applicability of the general category stereotype

\footnotetext{
${ }^{1}$ We conducted a qualitative pilot study with salespeople from three different industries in which social proofing and social comparisons emerged as two major tactics of salespeople supporting Ashforth \& Kreiner, (1999). We further validated the use of the tactics by examining the frequencies with which they are employed in various industries based on a sample of 205 salespeople, and validated measurement models for these tactics (see Web Appendix A; readers can find the supplementary web appendices on the Open Science Framework (OSF) page for this paper at https://osf.io/t3cqr/).
} 
should be reduced. Social comparison claims are hence aimed at disconfirming the occupational stereotypes of immorality to one's own occupational subgroup through self-favoring downward "us versus them" contrasts.

\section{Social Proofing}

Of the three tactics that are based on occupational ideologies, Ashforth and Kreiner (1999) argue that reframing has the strongest potential to thwart occupational stigma because it is aimed at transforming the very meaning of the work itself. Reframing can take multiple forms, but it generally involves members euphemizing their own subgroup's mission by restating the very purpose for which the subgroup or the work exists (Ashforth \& Kreiner, 1999). For instance, a salesperson may restate the purpose of their subgroup as 'serving and helping customers'. Such reframing of the subgroup's mission aims to challenge the perception that constituents' negative occupational stereotypes are applicable to that group. In frontline jobs, reframing the work in positive terms may be based on social proof rationales. Such rationales reflect instances of when the frontline employee's work has indeed been validated by others despite the stigma (cf. Ashforth \& Kreiner 1999). For instance, salespeople might reference high customer loyalty or high customer satisfaction or present favorable evidence from customer testimonials during sales encounters. For the perceiving customer, in turn, social proof rationales involve the heuristic that 'if many others are liking it, it must be good' (Cialdini \& Goldstein, 2004). Such social proof would contradict the evoked negative occupational stereotype of immorality and render it less applicable to the occupational subgroup.

In a next step we seek to theoretically derive how these tactics may relate to stigma and frontline employees' job performance. Figure 1a provides an overview of the proposed model and the hypotheses are presented in the sections that follow.

--- Insert Figure 1a about here --- 


\section{Moral Occupational Stigma and Stereotypes}

In order to conceptualize the links between stigma-countering and customers' occupational stereotypes of immorality, we draw from the expectancy-confirmation framework in the stereotyping literature (Darley \& Gross, 1983). We briefly describe the cognitive process underlying stigmatization and tie it to the stereotype expectancy-confirmation framework. Recall that morally stigmatized occupations are at the receiving end of stereotypes of immorality (see e.g., Crocker \& Major, 1989). When activated, these stereotypes will prompt tentative beliefs and expectancies about the traits and behavioral tendencies of the stigmatized individual that will guide the perceiver's judgment unless the perceiver has reasons to believe that they are not applicable (Hamilton, Sherman, \& Ruvolo, 1990). Stereotypes are typically activated in a relatively automatic fashion, upon an individual's initial encounter of a member of a given dubious category (e.g., Krieglmeyer \& Sherman, 2012). Upon initial perception, perceivers determine the applicability of the stereotypes associated with the stigmatized category to the target (Fiske \& Neuberg, 1990; Fiske, Neuberg, Beattie, \& Milberg, 1987). Upon further perception, perceivers observe verbal or behavioral cues from the focal category member and compare them against the stereotype evoked by the stigmatized category. When cues are stereotype-consistent, the stereotypes appear applicable to the target, and the stigma 'rubs off' on the actor (Bergman \& Chalkley, 2007). However, this unfolding comparison process is characterized by the tendency of the perceiver to find evidence in the stigma bearer's claims or behaviors supporting the initial stereotypical expectancies associated with the stigma (Darley \& Gross, 1983). Indeed, activated stereotypes can lead the perceiver to infer and process stereotype-consistent verbal or behavioral information to a greater extent than in the absence of stereotype activation (e.g., Fiske, 1998; Fyock \& Stangor, 1994; Macrae, Stangor, \& Milne, 1994). In this way, a stigma shifts the perceiver's interpretation of available information in a 
stigma-consistent direction, which facilitates unintentional confirmation and impedes intentional disconfirmation by targets (for a review see Nickerson, 1998 and Macrae \& Bodenhausen, 2000). When the stigma is transferred onto the actor, categorization was successful and the actor is believed to quintessentially possess the stereotypical traits.

\section{Stigma-Countering Tactics, Frontline Employee's Job Performance, and the Mediating Role of Customers' Occupational Stereotypes of Immorality}

We propose that while reframing through social proofing is instrumental for frontline workers' job performance because it is relatively successful in disconfirming customers' occupational stereotypes of immorality, social comparisons are detrimental for job performance because they ironically aid customers in confirming the occupational stereotype of immorality. Thus, we suggest that the effects of the countering tactics on job performance are channeled through changes in the application of occupational stereotypes.

Indeed, stereotypes can act as powerful mediators of perception and can bias social information (Duncan, 1976; Word, Zanna, \& Cooper, 1974). For example, experimental evidence shows that customers confronted with a stereotypical salesperson base their product evaluations on negative stereotypical beliefs about the occupational category rather than on information that they receive about the product itself (Sujan, Bettman, \& Sujan, 1986). Hence, it appears likely that strong stereotypes of immorality can lead customers to refrain from purchasing a product or service because they believe they are being tricked into spending money on something that does not satisfy their needs. Indeed, customers are more likely to buy a product if they have confidence that the frontline employee is acting in their best interest, as this perception increases customers' expected utility associated with the purchase (e.g., Homburg, Müller, \& Klarmann, 2011; Doney \& Cannon, 1997). Conversely then, stronger customer stereotypes of immorality are likely to lower customers' propensity to buy the product 
(McFarland, Challagalla, \& Shervani, 2006). Actual purchase behavior is an important performance variable for frontline employee's job performance (Cravens, Ingram, LaForge, \& Young, 1993), and so stereotypes of immorality are likely to harm frontline employees' job performance.

When it comes to countering these stereotypes, we propose that when frontline workers employ social proofing, they may disconfirm the stereotypes for customers and thereby improve their job performance. Conversely, with social comparisons, employees ironically confirm stereotypes of immorality for customers and unwittingly harm their job performance. We suggest that these tactics will have these effects for the following reasons. While social comparison claims ('at least we're not like them') might be accepted at face value when the actor does not carry a moral stigma, an actor with a moral stigma whose integrity is at stake is likely to be received negatively when employing such comparisons. Downward social comparisons due to their self-serving undertones can sometimes be interpreted negatively in their own right. For example, perceivers have been found to infer from a downward comparison that the claimant might not only view the comparison group negatively, but more generally holds a negative view of others (Hoorens et al., 2012; van Damme, Hoorens \& Sedikides, 2016), and that the claimant is a poor partner for social exchange (Hoorens et al., 2012). Such inferences are particularly likely when the perceiver views the frontline worker through the filter of moral stigma. The social comparisons are then likely to be taken as evidence of the frontline worker's questionable character. Hence, the worker using social comparisons is likely come to be seen as quintessentially immoral (cf. Mishina \& Devers, 2012). In this way, social comparisons can confirm the customers' stereotypes of immorality, which, in turn, may adversely affect frontline workers' job performance. 
By contrast, we suggest that social proofing may thwart the occupational stereotypes of immorality associated with the stigma. As we have noted, social proofing involves making references to value that has been created for existing customers, which we suggest will render the negative moral stereotype less applicable even when initially evoked by a frontline worker with a strong moral stigma. For example, frontline employees might reference evidence from customer testimonials or results of customer satisfaction surveys. From the customer's point of view, this input may indeed be informative when the frontline worker carries a stigma because it suggests the subgroup's counter-stereotypicality. In deriving their own judgments and to determine appropriate behavior for themselves, individuals often turn to others' opinions and experiences (e.g., Sridhar \& Srinivasan, 2012; Goldstein et al., 2008; Cialdini \& Goldstein, 2004). This search may include various sources, such as peers they do not know (Latane \& Darley, 1967) and others that needed to make similar decisions (Cohen, 2003). Thus, information indicating that other customers in this situation were satisfied constitutes information about the salespersons' accomplishment, and it should disconfirm the stereotype of immorality and render it less pertinent.

Accordingly, we hypothesize that when frontline workers employ social comparisons they will ironically confirm rather than disconfirm the stereotypes of immorality initially evoked by their occupational stigma, thereby unwittingly harming their job performance. In contrast, we hypothesize that when frontline workers employ social proofing, they will successfully thwart the stereotypes of immorality evoked by their occupation, which will benefit their job performance. We propose more formally:

Hypothesis 1a. A morally stigmatized frontline employee's inclination to use social comparisons is negatively associated with the frontline employee's job performance. 
Hypothesis 1 . A morally stigmatized frontline employee's inclination to use social proofing is positively related with the frontline employee's job performance.

Hypothesis $2 a$. The negative relationship between a frontline employee's inclination to use social comparisons and job performance will be mediated by customers' occupational stereotypes of immorality.

Hypothesis $2 b$. The positive relationship between a frontline employee's inclination to use social proofing and job performance will be mediated by customers' occupational stereotypes of immorality.

\section{The Moderating Role of Moral Stigma Intensity}

We suggest that the effects of the stigma-countering tactics on frontline workers' job performance via occupational stereotypes of immorality are contingent on the intensity of the moral stigma, such that the positive effect of social proofing and the negative effect of social comparisons on performance are weaker when the stigma is of low intensity versus when it is of high intensity. The key reason is that as a function of stigma-intensity, initial stereotypeactivation will vary in strength - it will be stronger with an intense stigma and weaker with a mild stigma. According to the stereotype expectancy-confirmation framework (Darley \& Gross, 1983), this will have two important downstream consequences. First, when stigma-intensity is low, interpretations of the acting frontline worker are shaped less by the stigma. In such cases, perceivers more readily believe that a claimant's statements are genuine or give the benefit of the doubt because they have little reason to believe otherwise (cf. Sagar \& Schofield, 1980). Second, the information conveyed through the countering claims becomes less relevant for the customer because initially there is little doubt about the frontline worker's integrity. Hence, countering claims will bring about very little informative value for the customer, even if received positively.

Based on this line of reasoning, we suggest more specifically for social comparisons that the conveyed information - even if believed to be genuine - will still have little relevance for the customer. When the frontline worker carries an intense moral stigma, however, the social 
comparisons are likely to be taken as evidence of the target's immorality because the initially activated occupational stereotype of immorality will shift the customer's interpretation of contrasting claims in a stereotype-consistent direction (e.g., Macrae \& Bodenhausen, 2000;

Bodenhausen 1988). Similarly, when the frontline worker is only mildly morally stigmatized, and initially the customer had very little doubt about the frontline worker's moral character, social proofing claims might still be received positively, but are likely to carry little relevant informative value with respect to stereotypes of immorality for the customer and may hence excerpt only very little effects on the frontline workers' performance. We therefore hypothesize the following:

Hypothesis $3 a$. There is a conditional indirect effect between a morally stigmatized frontline employee's inclination to use social comparisons and job performance via customers' stereotypes of immorality, such that the negative indirect effect of social comparisons on job performance is less negative when the occupational stigma is mild compared to when it is strong.

Hypothesis $3 b$. There is a conditional indirect effect between a morally stigmatized frontline employee's inclination to use social proofing and job performance via customers' stereotypes of immorality, such that the positive indirect effect of social proofing on job performance is less positive when the occupational stigma is mild compared to when it is strong.

\section{OVERVIEW OF STUDIES}

We tested the theoretical model depicted in Figure 1a across three main studies. The aim of Study 1 is to test hypotheses $\mathrm{H} 1 \mathrm{a}$ and $\mathrm{H} 1 \mathrm{~b}$, using longitudinal data of one industry, and reports direct effects of the stigma-countering tactics on frontline workers' job performance. The main goal of Study 2 is to test hypotheses $\mathrm{H} 2 \mathrm{a}$ and $\mathrm{H} 2 \mathrm{~b}$ in a cross-industry sample of frontline employees and customers using a different facet of frontline employees' job performance. Study 3 then reports the results of an experiment that extends findings from Study 1 and Study 2 by further providing a test of $\mathrm{H} 3 \mathrm{a}$ and $\mathrm{H} 3 \mathrm{~b}$. 


\section{STUDY 1}

We designed Study 1 with the goal in mind of testing H1a and H1b so as to shed initial light on the job-performance implications that countering a moral stigma may have. For this purpose, we conducted a study in the fashion retailing industry. We chose this industry because salespeople in fashion retailing have been found to be associated with particular negative traits and ascriptions of immoral behavioral tendencies (Sujan, Bettman, \& Sujan, 1986) and are thus likely to engage in stigma-countering. We operationalized job performance discretely as transaction value achieved in a business exchange. Being related to the amount at stake, transaction value per transaction reflects a frontline employee's ability to convince customers to buy more expensive products (i.e., up-selling) and to convince customers to buy ancillary products in addition to a core product (i.e., cross-selling, e.g., Ahearne, Jelinek, \& Jones, 2007; Reynolds \& Beatty, 1999). We analyze job performance over a prolonged time span of one year, which allows us to assess the temporal continuity of the effects of stigma-countering.

\section{Methodology}

Context. For Study 1, we cooperated with an apparel brand in Europe. The brand owns manufacturing facilities for producing clothes and distributes the products through a network of retail stores, which it owns. Each store is led by a sales manager and typically employs three to five frontline employees. The product portfolio of the brand comprises all major clothing categories, such as trousers, shirts, t-shirts, and jackets.

Data collection and sample. We asked each frontline employee of the apparel brand to complete a questionnaire about general perceptions and attitudes concerning his or her job as well as his or her inclinations to use social proofing and social comparisons. Additionally, we obtained data on the transaction value per transaction with a customer from the retailer's data base. The transaction value per individual customer transaction was matched to the individual 
frontline employee through personal identification numbers, which the fashion retailer provided. These numbers linked the archival transaction data with the survey data.

We received usable survey responses of 131 frontline employees for a response rate of $79 \%$. We matched frontline employees' individual responses with the individual total transaction value of the respective frontline employee generated over multiple customer interactions over one year. Specifically, on average, frontline employees had 981.2 transactions with customers in the focal year, with a minimum of 732 customer transactions per frontline employee per year and a maximum of 3,556 customer transactions per frontline employee per year. The average age of frontline employees was 33.6 years, the average job experience was 12.1 years, (ranging between 1 and 32 years), and $72 \%$ of the frontline employees were female.

Measurement of social proofing and social comparisons. All measurement scales employed in this study are detailed in Appendix A. In order to operationalize the countering tactics, we blended current theory on occupational countering tactics (Ashforth \& Kreiner, 1999) with findings from semi-structured, in-depth interviews with salespeople from three industries. On the basis of the interviewees' reports and extant research, we operationalized social proofing and social comparison claims (see Web Appendix A). The final scale includes three items for each tactic indicating the degree to which salespeople were inclined to practice the tactics on seven-point Likert scales. Items for both tactics were preceded by an introductory sentence ("If you feel that your customers harbor negative stereotypes toward you (e.g., 'a sleazy salesperson'), what do you do to rebut these stereotypes?'). For the purpose of Study 1, an index for both scales was created (social proofing, $\alpha=.70$; social comparisons, $\alpha=.70$ ). The full measures are reported in Appendix A. 
Measurement of outcome variable and covariates. For transaction value per customer transaction, we used archival data from the firm`s data base. To normalize the distribution of the transaction value per transaction, we logged the values of this variable. We controlled for the following variables at the frontline employee level for their effects on the transaction value per transaction: customer orientation, which represents frontline workers' desire to understand and meet customer needs (Saxe \& Weitz, 1982), perceived competitive intensity, job experience, age, and gender. We relied on operationalizations based on prior research. Specifically, we measured perceived customer orientation using the six items of the well-established scale of Thomas, Soutar, and Ryan (2001); an index was calculated (customer orientation, $\alpha=.91$ ). We measured perceived competitive intensity using one item from Jaworski and Kohli (1993), on which frontline employees were asked to state on a seven-point scale the extent to which they agreed with the statement, "Price competition is a hallmark of our industry." The remaining control variables at the frontline employee level were assessed with simple direct questions. The control variables at the customer transaction level — the month in which the customer transaction occurred and the number of purchased articles - were taken from the firm database. The month in which the customer transaction occurred is included in the model estimation at the withinlevel of the model through 11 dummy variables, with January as reference month.

Psychometric properties of the employed scales appear in Table 1. We followed established procedures for confirmatory factor analyses and entered all multi-item scales into one measurement model that was simultaneously estimated, i.e., the scales for social proofing, social comparisons, and customer orientation (Bagozzi \& Yi, 1988). We extracted fit indices and factor loadings from this model and calculated reliability diagnostics. Results suggest a good overall fit $\left(\mathrm{CFI}=.95 ; \mathrm{RMSEA}=.002 ; \mathrm{SRMR}=.08 ; \chi^{2} / \mathrm{df}=1.62\right)$ with all average variances extracted 
(AVE) exceeding the value of .50 (Bagozzi \& Yi, 1988). In addition, the squared correlations between the latent constructs are smaller than the average variance extracted from each construct, which suggests discriminant validity of the scales (Fornell \& Larcker, 1981). Overall, these results indicate that our measurement scales possess convergent and discriminant validity as well as adequate reliability.

--- Insert Table 1 about here ---

\section{Results of Study 1}

Analytical approach. Our study comprises 128,549 customer transactions over one year that are nested in 131 frontline employees from 35 stores. Because a single frontline employee engaged in multiple transactions over the one-year period that we are investigating, the observations in the data set are not independent from each other. Again, to account for the nested data structure, we used hierarchical linear modeling to test our hypotheses (Raudenbush \& Bryk, 2002). Specifically, we estimated a two-level path model using Mplus software (Version 7; Muthén \& Muthén, 1998-2017) and a full information maximum likelihood estimator with robust standard errors. We further controlled for the nesting of frontline employees within stores by employing a so-called sandwich estimator to compute adjusted standard errors and test statistics to take into account non-independence of observations due to store-level nestings (Muthén \& Muthén, 1998-2017).

We first ran a null model without any explanatory variables. This analysis revealed that $10 \%$ in value per customer transaction resides at the frontline employee level $(\mathrm{ICC}=.10)$, which suggests that our model should statistically address the non-independence of the individual transaction data (Bliese, 2000). Hence, we proceeded to specify the full multilevel path model.

In the model, variables measured at the frontline employee level (social proofing, social comparisons, customer orientation, perceived competitive intensity, job experience, age, and 
gender) reside at the between level, while variables related to the individual customer transactions (transaction value per customer transaction, number of articles purchased, and month of customer transaction) reside at the within level. We centered all continuous predictor variables on their grand means prior to model estimation and allowed covariances between the independent variables in the model. Results appear in Table 2.

--- Insert Table 2 about here ---

Results show that there is a negative effect of social comparisons $(b=-.034, p<.01)$ and a positive effect of social proofing on transaction value per transaction with a customer $(b=.027$, $p<.05)$, supporting our hypotheses H1a and H1b. We ran the model with and without control variables, and results remain stable.

\section{Discussion of Study 1}

The results of Study 1 support Hypotheses 1a and 1b, and thus show that while social proofing emerges as an effective stigma-countering tactic, social comparisons harm salespeople's job performance. Study 1, however, is incomplete in that it only tests direct effects of the countering tactics on frontline workers' job performance. In a next step, we built on these results and aimed to extend them by shedding light on the mechanism that may underlie the link between stigma-countering and negative occupational stereotypes.

\section{STUDY 2}

The main purpose of Study 2 was to test Hypotheses $2 a$ and $2 b$, i.e., that the effects of the stigma-countering tactics on employees' job performance are mediated by stereotypes of immorality. To this end we collected a cross-industry sample of salespeople and customers across different retail contexts, which should further enhance the generalizability of our findings.

\section{Methods}


Research setting. A portion of the cross-industry data for Study 2 was gathered as part of a larger data collection effort by the second author. This portion involves the data from customers and frontline employees in industries other than car retailers. Findings from the larger data collection have been reported as Study 1 in a separate article (Alavi, Habel, Schmitz, Richter, \& Wieseke, 2018; Study 1), involving data from 139 customers and 72 frontline employees. This study addresses a different research question, and none of the substantive variables (i.e., independent variables, mediator, and dependent variable) overlap across studies.

Sample. Members of our research team administered questionnaires to the salespeople in their respective branches. They completed the questionnaires immediately and handed them back to the members of the research team. Customers were approached by members of our research team directly after they engaged in a sales encounter with the salespersons at the focal retailers and they were asked to complete a questionnaire. Of the approached customers, $45 \%$ agreed to participate, as did $100 \%$ of the salespersons, as they were strongly encouraged by the management. 32 salespersons had missing data on both stereotype-countering tactics. We therefore dropped their responses and responses of their respective customers (i.e., list-wise deletion). Data from electronic retailers were not considered for the present investigation. The resulting sample size consisted of observations from 535 customers ( $36.1 \%$ female; mean age of 43.15 years) and 161 salespeople (19.4\% female; mean age of 37.36 years). Questionnaires were matched using code numbers.

\section{Measures}

Social proofing and social comparisons. Regarding the scales for social proofing and social comparisons, we utilized the same measures as in Study 1. An index for both scales was created (social proofing, $\alpha=.70$; social comparisons, $\alpha=.72$ ).

Occupational stereotypes of immorality. We measured customers' occupational 
stereotypes of immorality using items of the stereotype content model (Fiske et al., 2002, 1999). We chose to focus on the moral facet of the warmth dimension, which reflects attributes pertaining to the evaluation of a group as being 'good' (Leach, Ellemers, and Barreto, 2007), to "breaking or maintaining moral rules and/ or ... doing good or bad things to others" (Wojciszke, Bazinska, \& Jaworski, 1998: 1253). We employed positive morality statements and then recoded them because prior research suggests that people respond more accurately to sensitive topics such as stereotypes about groups when the statements are positive (Marsh, 1996; Savary, Goldsmith, \& Dhar, 2015; Schmitt \& Allik, 2005). The items hence serve as amalgam measure of the various malevolent traits, behavioral tendencies, and intentions relevant to a moral stigma (Hartman, 2006; Ingram \& Schwepker, 1993; Baldwin, 1992). An index was calculated (occupational stereotypes of immorality, $\alpha=.90$ ).

Outcome variables. Actual purchase was measured with one dichotomous item: Customers indicated whether they actually had purchased the product for which they had come to the retailer's shop.

Covariates. To control for factors that have been argued to influence stereotypes and the consequences of stereotyping, we included a series of control variables into our model. Because acquaintance may suppress the application of stereotypes, we controlled for the length of the relationship between a frontline employee and a customer (e.g., Pettigrew, Christ, Wagner, \&, Stellmacher, 2007). We measured relationship length with an item from Bell, Auh, and Smalley (2005) and asked customers to indicate for how many years they had known the frontline employee. We also control for customer age and gender, and the individual's risk aversion, using an item from Mandrik and Bao (2005), "I do not feel comfortable taking risks". To isolate the effects of the stigma-countering tactics, we controlled for the general sentiment of the interaction 
as perceived by the customer, which we assessed using an item asking customers to indicate the extent to which they agreed that "the interaction was pleasant" on a seven-point scale. We also controlled for customers' category experience as it may affect the role customers ascribe to the frontline employee in the buying process (Busch \& Wilson, 1976). We assessed customer category experience by asking customers to state how many [focal product] they had previously bought in total. We also controlled for perceived customer orientation and perceived product quality as important determinants of purchase behavior. To measure perceived product quality, we used an item from Grewal, Monroe, and Krishnan (1998) and asked customers to indicate on a seven-point scale the extent to which they agreed with the following statement: "The [product] appears to be of good quality." We also asked customers to indicate perceived customer orientation using the six items from Study $1(\alpha=.91)$. Finally, we controlled for frontline employees' age, which we measured using one simple item on the salesperson questionnaire.

\section{Measure Assessment}

Table 3 provides an overview of the means, standard deviations, correlations, and scale reliabilities.

We followed established procedures for confirmatory factor analyses and entered all multi-item scales, i.e., those of social proofing, social comparisons, customer orientation, and negative occupational stereotypes into one measurement model that was simultaneously estimated (Bagozzi \& Yi, 1988). We extracted fit indices and factor loadings from this model and calculated reliability diagnostics. Results suggest a good overall fit $(\mathrm{CFI}=.95 ; \mathrm{RMSEA}=$ $\left..05 ; \mathrm{SRMR}=.05 ; \chi^{2} / \mathrm{df}=2.56\right)$ with all average variances extracted (AVE) exceeding the suggested cut-off point (Bagozzi \& Yi, 1988) and squared correlations between the latent constructs being smaller than the average variance extracted for each construct, which suggests discriminant validity of the scales (Fornell \& Larcker, 1981). Furthermore, Cronbach's alpha 
values of the scales indicate sufficient reliability (Nunnally, 1978). Overall, these results suggest that these scales possess adequate reliability as well as reasonable convergent and discriminant validity.

--- Insert Table 3 about here ---

\section{Analytical Approach}

Our model contains hierarchical data, such that customers (within level) are nested within frontline employees (between level), which in turn are nested in branches and different industries. Thus, we used hierarchical linear modeling to test our hypotheses (Hox, 2010; Raudenbush \& Bryk, 2002). While we explicitly modeled within-level 1 and between-level 2 because they are of theoretical interest for our investigation, we handle the third level (branches)

by employing the same sandwich estimator as in Study 1 to compute adjusted standard errors and test statistics to account for the dependence due to third-level nestings (Muthén \& Muthén, 1998-2017). Furthermore, our model includes industry-fixed effects, which are represented by dummy-coded variables.

We estimated a multilevel path model with a binary outcome, i.e., job performance. The path model allows simultaneous estimation of all specified paths, using the software Mplus 7 (Muthén \& Muthén, 1998-2017). Beyond the hypothesized links and controlled relationships, we also estimated covariances between the exogenous customer as well as the exogenous salesperson variables at their respective levels to account for potential dependencies between them. We employed robust ML estimation and Monte Carlo integration. Prior to model estimation we grand mean centered all continuous explanatory variables (Kreft, de Leeuw, \& Aiken, 1995; Snijders \& Bosker, 1999).

\section{Results of Study 2}


Model development. Prior to model specification, we determined the extent to which our criterion variable purchase behavior varies among frontline employees. This analysis revealed that $30 \%$ of the variance in purchase behavior resides at the salesperson between-level $($ ICC $=$ .30 ), which suggests that our model should statistically address the non-independence of the individual customer observations (Bliese, 2000). In a next step, we specified the full hypothesized multilevel path model. Table 4 provides an overview of the estimation results.

--- Insert Table 4 about here ---

Hypothesis testing. Results show that frontline employees' inclination to practice social comparisons is associated with stronger occupational stereotypes of immorality $(\mathrm{b}=0.087 ; p<$ $.05)$ whereas a stronger inclination to practice social proofing is associated with weaker occupational stereotypes of immorality $(\mathrm{b}=-0.082 ; p<.05)$. Furthermore, we find a significant negative relationship between customers' occupational stereotypes of immorality and customers' purchase behavior $(\mathrm{b}=-0.249 ; p<.05)$. A mediation analysis reveals a negative indirect effect of the inclination to employ social comparisons on purchase behavior via occupational stereotypes of immorality (indirect effect: $b=-0.022,90 \% \mathrm{CI}:-0.043,-0.001$ ) and a positive indirect effect of the inclination to employ social proofing (indirect effect: $b=0.020,90 \%$ CI: $0.001,0.041$ ), in line with Hypotheses H2a and H2b.

\section{Discussion of Study 2}

The results we have triangulated across two studies so far suggest two key implications. First, frontline employees in the field engage in stigma-countering through social proofing and social comparisons. Second, while social proofing appears to be a functional tactic, social comparison claims appear to backfire such that they increase negative stereotyping. While Study 2 was conducted using multiple-source data from different industries, it would still not allow us to draw causal inferences about the role of stigma and countering tactics. In a next step, we 
hence conducted an experiment manipulating stigma through different frontline jobs as well as manipulating the stigma-countering tactics themselves. More specifically, we aim to conceptually replicate the indirect effects from Study 2 in a more controlled setting and seek to extend them by testing the Hypotheses $3 \mathrm{a}$ and $3 \mathrm{~b}$. That is, when the frontline job is associated with a strong moral stigma, stigma-countering tactics affect employees' job performance more profoundly because they have a larger effect on the evoked category stereotype of immorality than when the frontline job is only mildly morally stigmatized.

\section{STUDY 3}

\section{Method}

We randomly allocated participants to six conditions in a 3 (stigma-countering tactics: control, social proofing, social comparisons) x 2 (moral stigma of the frontline job: high moral stigma intensity vs. low moral stigma intensity of the frontline job) between-subjects design. We determined sample size for the experiment based on an a priori power analysis (see Web Appendix B). We recruited 860 UK-based participants through the online panel provider Prolific for a payment of $0.40 \mathrm{GBP}$. We dropped responses from 23 participants because they failed to correctly respond to an attention check (in the attention check we had asked participants to "please strongly agree with this item") and responses from 17 participants due to missing values on the dependent variables arriving at a final sample of 820 participants $(70.7 \%$ female; mean age of 38.46 years). The first experimental factor manipulates the countering tactics and comprises a control condition, a social proofing condition, and a social comparison condition. The second experimental factor manipulates the frontline jobs, which are associated with relatively high versus relatively low intensity of the moral stigma.

Procedure. The experiment is situated in a furniture retailing context. To develop experimental scenarios with sufficient realism, we initiated a cooperation with a local furniture 
store. We asked participants to assume the role of a customer who is interested in buying a couch. To this end, the customer would visit a furniture store. We then exposed participants to the written experimental scenarios, in which the customer encounters a frontline worker of the furniture store who consults him or her on different product options. During this consultation, the frontline worker deploys one of the stigma-countering tactics. All scenarios appear in Web Appendix D.

For manipulating the countering tactics, we developed scripts for how the tactics could most realistically be described in a scenario and revised them based on a discussion with a salesperson working for the furniture store we cooperated with. In the social comparison condition, the frontline worker provides product information and, additionally, informs customers that, unlike in other furniture stores where salespeople focus only on closing a deal, this store focuses on providing high quality consultation to customers. In the social proofing condition, the salesperson provides product information, and informs that customers in the past were satisfied with the store's products and services, and tended to continue to patronize it, which is documented by positive ratings on customer review websites. In the control conditions, the frontline worker does not engage in any countering tactic and provides merely product information to the customers.

For manipulating frontline jobs with high and low intensity of moral stigma, we stated in the scenarios that customers either interact with a 'salesperson' (high intensity condition) or with an 'employee' of the store (low intensity condition). A pretest with 59 UK-based respondents recruited through the crowd-sourcing provider Prolific confirmed that participants have significantly higher concerns about the salesperson's morality than about the employee's morality $\left(F(1,57)=5.836, p<.05 ; \mathrm{M}_{\text {salesperson }}=3.61, \mathrm{M}_{\text {employee }}=2.60\right)$. 
Measures. After respondents had been exposed to the scenarios, we asked them to respond to scales on occupational stereotypes of immorality $(\alpha=.84)$, their purchase intentions, manipulation check items, and demographics. In this study, the experimental treatment factors of stigma-countering tactics and intensity of moral stigma represent the independent variables, which we include in the analysis as group-coded dummy variables. For the path model to estimate conditional indirect effects, we employed a group-code approach and introduced two binary dummy-variables to represent participants' membership in one of the stigma-countering tactics conditions: a social proofing dummy (with social proofing coded as ' 1 ' and the control group coded as ' 0 '), a social comparison dummy (social comparisons coded as ' 1 ' and the control group coded as ' 0 '), and a frontline job dummy (with the high stigma frontline job coded as ' 1 ').

Regarding the dependent variables, we measured customers' occupational stereotypes of immorality with the same three items as in Study 2, using 7-point Likert-scales (Fiske et al., 2002, 1999). As with Study 2, we reverse coded the items for the analysis. A confirmatory analysis of this scale indicates sufficient reliability (average variance extracted $=.65$; composite reliability $=.85)$. We assessed employees' job performance using an item that measured participants' likelihood of purchasing at this retailer, ranging from very low to very high. Furthermore, we surveyed participants on the variable negative stereotype confirmation to scrutinize the conceptual mechanism underlying the results. We report details on the measurements in Appendix A.

\section{Results}

Manipulation Checks. In a first step, we tested whether the manipulation of the stigmacountering tactics worked as intended. To this end, we conducted a pretest of the stigmacountering manipulations, and recruited 151 UK-based participants from the crowdsourcing 
provider Prolific who we randomly allocated to the three treatment conditions (social proofing, social comparisons, and control; see Web Appendix D). Participants rated the tactics employed by the salesperson depicted in the treatment conditions on the same stigma-countering tactics scales we had employed in Study 1 and Study 2. The items appear in Appendix A, with the only adjustments being that items were formulated from observers' perspective and the word 'branch' in the original items was replaced with the word 'store'. (A sample item of social comparisons is accordingly: "The salesman pointed out that the stereotypes might apply to salespeople of other companies, but not to the salespeople of this store."; a sample item of proofing is: "The salesman pointed out that many of the customers of this store are satisfied and were not tricked.") The manipulations have worked as intended. In the social comparison condition, participants felt that social comparisons were stronger than in the two other conditions $(F(2,148)=107.28, p<.01$; $\eta^{2}=.59, \mathrm{M}_{\text {Control }}=1.91 ; \mathrm{M}_{\text {Comparisons }}=5.69, \mathrm{M}_{\text {Proofing }}=3.44 ; \Delta \mathrm{M}_{\text {Comparisons vs. control }}=3.78, \mathrm{SE}=$ $.26, \mathrm{CI}[3.27,4.30], F(1,148)=210.72, \eta^{2}=.59, p<.01 ; \Delta \mathrm{M}_{\text {Comparisons vs. proofing }}=2.25, \mathrm{SE}=.26$, $\left.\mathrm{CI}[1.75,2.76], F(1,148)=77.22 ;, \eta^{2}=.34, p<.01\right)$. Accordingly, in the social proofing condition, participants sensed that social proofing was stronger than in the two other conditions $\left(F(2,148)=85.16,, \eta^{2}=.53, p<.01 ; \mathrm{M}_{\text {Control }}=1.94 ; \mathrm{M}_{\text {Comparisons }}=2.67, \mathrm{M}_{\text {Proofing }}=5.10 ;\right.$ $\Delta \mathrm{M}_{\text {Proofing vs. control }}=3.16, \mathrm{SE}=.26, \mathrm{CI}[2.69,3.66], F(1,148)=153.43, \eta^{2}=.51, p<.01$; $\left.\Delta \mathrm{M}_{\text {Proofing vs. comparisons }}=2.43, \mathrm{SE}=.25, \mathrm{CI}[1.93,2.92], F(1,148)=94.11 ; \eta^{2}=.39, p<.01\right)$. Analytical Approach. For testing our hypotheses, we used ANOVAs and a path model for estimating and bootstrapping conditional indirect effects. Table 5 provides an overview of the correlation matrix and descriptive information.

--- Insert Table 5 about here --- 
In $\mathrm{H} 3 \mathrm{a}$ and $\mathrm{H} 3 \mathrm{~b}$, we predict that the indirect effect of social proofing and social comparisons on frontline employees' job performance (operationalized as customer purchase intentions in this study) via customers' negative occupational stereotypes of immorality is conditional on the intensity of the moral taint that is associated with the frontline job. Prior to formally testing these conditional indirect effects, we first inspected direct effects of the treatments on employee job performance and on the mediator customers' occupational stereotypes of immorality. We specified an ANOVA with job performance as dependent variable and the experimental factors as independent variables. Estimation was carried out using STATA 15.1. Results show a marginal significant main effect of the stigma-countering tactics and a nonsignificant main effect of the occupational stigma intensity manipulation $\left(F_{\text {tactics }}(2,814)=2.85\right.$, $\left.\eta^{2}=.007, p<.10 ; \mathrm{F}_{\text {job stigma }}(1,814)=2.16, \eta^{2}=.003, \mathrm{~ns}\right)$. Importantly, we find a significant interaction effect of the stigma tactic factor and moral stigma intensity on customers' purchase intentions $\left(F(2,814)=3.82, \eta^{2}=.009, p<.05\right.$. To probe deeper into this pattern of results, we inspected post-hoc contrasts. The contrasts indicate that for the frontline job with an intense moral occupational stigma, social proofing leads to significantly higher purchase intentions compared with the control condition $\left(\Delta \mathrm{M}=.31, \mathrm{SE}=.15, \mathrm{CI}[.02, .59], \mathrm{F}(1,814)=4.33, \eta^{2}=\right.$ $.005, p<.05)$. For the frontline job with low moral stigma intensity, the level of customer purchase intentions does not significantly differ between the social proofing and the control condition $\left(\Delta \mathrm{M}=-.16, \mathrm{SE}=.15, \mathrm{CI}[-.45, .13], \mathrm{F}(1,814)=1.20, \eta^{2}=.001\right.$, ns $)$. Turning to the social comparison condition, for high moral stigma intensity, purchase intentions are lower compared with the control condition, but the difference is not significant $(\Delta \mathrm{M}=-.20, \mathrm{SE}=.15$, $\mathrm{CI}[-.49, .09], \mathrm{F}(1,814)=1.92, \eta^{2}=.002$, ns). Similarly, for low moral stigma intensity, purchase 
intentions do not significantly differ between the social comparison and the control condition $\left(\Delta \mathrm{M}=-.14, \mathrm{SE}=.15, \mathrm{CI}[-.44, .15], \mathrm{F}(1,814)=.90, \eta^{2}=.001, \mathrm{~ns}\right) .^{2}$

In a next step, we estimated an ANOVA with customers' occupational stereotypes of immorality as dependent variable and the treatment factors as independent variables. Results show a significant main effect of the stigma-countering tactics $\left(F(2,814)=3.53, \eta^{2}=.009, p<\right.$ $.05)$, and a marginal significant main effect of the occupational stigma intensity manipulation $\left(F(1,814)=3.73, \eta^{2}=.005, p<.10\right)$. Importantly, in line with our theorizing, the interaction effect of the stigma-countering tactics by moral stigma intensity (high vs. low) on negative occupational stereotypes of immorality is significant $\left(F(2,814)=13.98, \eta^{2}=.033, p<.01\right)$. Since we hypothesized negative occupational stereotypes to be the mediator, we probed into this pattern of results deeper using post-hoc contrasts. Results indicate that for the occupation with high moral stigma intensity, social comparison leads to significantly higher negative occupational stereotypes of immorality compared with the control condition $(\Delta \mathrm{M}=.32, \mathrm{SE}=$ $\left..12, \mathrm{CI}[.07, .56], \mathrm{F}(1,814)=6.56, \eta^{2}=.008, p<.05\right)$. By contrast, social proofing leads to significantly lower negative occupational stereotypes of immorality compared with the control condition $\left(\Delta \mathrm{M}=-.38, \mathrm{SE}=.12, \mathrm{CI}[-.63,-.14], \mathrm{F}(1,814)=9.67, \eta^{2}=.012, p<.01\right)$. For the job with low moral stigma intensity, neither social comparisons nor social proofing exhibit significant effects on negative occupational stereotypes of immorality (social comparisons: $\Delta \mathrm{M}$ $=-.09, \mathrm{SE}=.13, \mathrm{CI}[-.34, .15], \mathrm{F}(1,814)=.56, \eta^{2}=.000, \mathrm{~ns} ;$ proofing: $\Delta \mathrm{M}=.14, \mathrm{SE}=.12, \mathrm{CI}[-$ $\left..11, .38], \mathrm{F}(1,814)=.1 .22, \eta^{2}=.001, \mathrm{~ns}\right)$. While these results provide initial support for our

\footnotetext{
${ }^{2}$ Furthermore, we estimated contrasts between the social proofing and social comparison condition. The contrasts indicate that with high stigma intensity social proofing leads to significantly higher purchase intentions compared with the social comparison condition $\left(\Delta \mathrm{M}=.51, \mathrm{SE}=15, \mathrm{CI}[.22, .80], \mathrm{F}(1,814)=11.56, \eta^{2}=.014, p<.01\right)$. For low moral stigma intensity, the level of customer purchase intentions does not significantly differ between the social proofing and comparison condition $\left(\Delta \mathrm{M}=-.02, \mathrm{SE}=15, \mathrm{CI}[-.31, .27], \mathrm{F}(1,814)=.894, \eta^{2}=.001\right.$, ns $)$.
} 
theorizing, to fully test our hypotheses we conducted a moderated mediation analysis and tested for conditional indirect effects.

Conditional Indirect Effects. We used the Mplus software (Version 7; Muthén \& Muthén, 1998 -2017) and specified a path model as depicted in Figure 1b. We used established procedures recommended for this type of mediation analysis (Preacher, Rucker, \& Hayes, 2007; Shrout and Bolger 2002). Turning to the hypotheses tests, we first examined the global model fit, which indicates that the model fits the data well $(\mathrm{CFI}=1.00 ; \mathrm{TLI}=1.00 ; \mathrm{SRMR}=.00 ; \mathrm{RMSEA}$ $=.02$ ). To test our mediation hypotheses, we bootstrapped standard errors of parameter estimates and estimated confidence intervals (CI) for the indirect and direct effects (MacKinnon, Lockwood, and Williams 2004). Results show that for the frontline job with a strong moral stigma, social comparisons exhibit a negative indirect effect on customer purchase intentions via customers' negative occupational stereotypes of immorality $\left(\beta_{\text {indirect }}=-.075, \mathrm{CI} 95 \%=[-.131\right.$, $.018], p<.05)$. Social proofing, in turn, exhibits a positive indirect effect on customer purchase intentions via customers' negative occupational stereotypes of immorality $\left(\beta_{\text {indirect }}=.091, \mathrm{CI}\right.$ $95 \%=[.028, .154], p<.05)$. However, for frontline jobs with low moral stigma intensity, neither social comparisons nor social proofing exhibit significant indirect effects on customers' purchase intentions $\left(\beta_{\text {indirect comparisons }}=.022, \mathrm{CI} 95 \%=[-.032, .077], \mathrm{ns} ; \beta_{\text {indirect proofing }}=-.032, \mathrm{CI} 95 \%=[-\right.$ $.090, .025], \mathrm{ns})$. Overall, this pattern of results supports H3a and H3b. Furthermore, the direct effects of social comparisons and social proofing on stereotypes of immorality are insignificant in the mediation model for low and high moral stigma intensity, indicating full mediation for high moral stigma intensity. Figure $1 \mathrm{~b}$ provides a comprehensive overview of the main results of 
the estimation, and Table 6 reports details of the mediation analyses. ${ }^{3}$ The full results of the path model appear in Web Appendix B.

--- Insert Figure $1 \mathrm{~b}$ about here ---

--- Insert Table 6 about here ---

\section{Discussion of Study 3}

In Study 3, we find that the extent to which the countering tactics impact frontline employees' job performance via customers' occupational stereotypes of immorality is dependent on stigma intensity. Importantly, the mediation chains only hold when the frontline job is strongly stigmatized, which lends support to our theorized logic that the effects of stigmacountering on job performance are mediated through stereotypes of immorality as when these are weak as in the low stigma-intensity condition, the mediation effect drops to non-significance. While experiments have advantages in terms of control over independent variables they can have disadvantages in terms of external validity (Bateson \& Hui, 1992). In concert with the two field studies, however, we have triangulated converging evidence supporting our theoretical claims.

\section{GENERAL DISCUSSION}

\section{Theoretical Implications}

This study extends the literature on dirty work and carries important implications for the broader literature on stigma management. We examine the outward-facing consequences of two stigma-countering tactics identified in the dirty work literature in the perceiver and link them to

\footnotetext{
${ }^{3}$ In addition, we conducted an additional analysis to test whether the frontline worker is perceived to confirm versus disconfirm customer occupational stereotypes of immorality. To this end, we repeated the analysis of conditional indirect effects, and additionally included customers' negative stereotype confirmation as mediator in the stigmacountering tactic - customers' negative occupational stereotypes of immorality linkage. We had assessed this variable with a 7-point semantic differential scale item, asking respondents to state whether "salesperson's communication..." ... disconfirmed my negative stereotypes against salespeople" to "...confirmed my negative stereotypes against salespeople". Results, fully reported in Web Appendix C, corroborate our previous results. They further indicate the mediating role of customers' negative stereotype confirmation.
} 
job performance of the bearer. In doing so, we provide a more nuanced understanding of the consequences of behaviors aimed at overcoming negative stereotyping and stigmatization.

The prevailing orthodoxy in the literature on dirty work suggests that countering a stigma enables dirty workers to perform their task with reduced burden of that stigma (Ashforth et al., 2007). This conclusion is mainly based on empirical studies that have investigated the intrapsychic consequences of stigma-countering for the bearer, but that have sidestepped the consequences of countering a stigma in interactions with occupational outsiders (e.g., Ashforth et al., 2007; Grandy, 2008; Dick 2005). With the focus on outward-facing consequences of stigmacountering, it becomes apparent that countering an occupational stigma is more complex and intricate than previously assumed. In fact, it appears to be a double-edged sword that can have unintended negative consequences for the stigma bearer, such that countering attempts with occupational outsiders can backfire and reinforce the initial stigma.

This finding has further implications with respect to extant theory on dirty work. The central dilemma of dirty work occupations is for their members to gain the social affirmation for their work that society denies them (Ashforth \& Kreiner, 1999). Past research shows that while they might be fairly successful in protecting the self against internalizing negative stereotypes, our work suggests that it might be more difficult for them to prevent occupational outsiders from viewing them in terms of the negative category stereotypes associated with their occupational stigma. Understanding these outward-facing consequences of stigma management therefore yields a fuller understanding of the phenomenon of dirty work.

It is of worth noting that initial conceptual research on dirty work has suggested that stigma-countering tactics are effective in creating internal and external affirmation alike (Ashforth \& Kreiner, 1999). This earlier model, however, is not supplemented with a theory on 
how stigma-countering might be received by a perceiver and thus may have arrived at the conclusion that stigma-countering renders a dirty occupation palatable for both, insiders and outsiders. Our arguments highlight the importance of the perceiver's tendency to find evidence in the stigma bearer's claims supporting the initial stigma, which helps to explain why outwardfacing stigma-countering can backfire.

Another interesting aspect of our finding that stigma-countering can have the opposite of the intended effects is that it represents a new path for how negatively stereotyped and stigmatized individuals may unwittingly reinforce others' negative reactions to them (e.g., Dovidio, 2001; Goffman, 1963; Kleck, 1969). Our work broadens the scope of behaviors that could potentially lead to unintentional stigma reinforcement from nonverbal behaviors from which the perceiver might infer a negative response to the interaction, such as increased fidgeting (e.g., Dovidio, 2001), to include behaviors that are based on the actor's intentional motivation. These deliberate behaviors are arguably easier to alter than subconsciously motivated behaviors because they are based on the stigmatized workers' conscious intent.

Our study also holds interesting implications at the level of specific stigma-countering tactics. While prior work has found that downward social comparisons are effective in protecting the worker's self from internalizing negative stereotypes associated with the stigma (e.g., Ashforth et al., 2007), our findings suggest that at the interpersonal level, downward social comparisons appear to be dysfunctional and reinforce the occupational stigma. Thus, a key finding of our work is that when used in an outward-facing context, social comparisons can bring about unintended negative consequences, such that they contribute to the worker's stigmatization. 
Our findings further highlight that the intensity of stigma has important consequences for stigma management - a notion currently underrepresented in the literature (Kreiner, Ashforth, \& Sluss, 2006). Social proofing and social comparison claims appeared to be non-diagnostic when the focal employee was only mildly stigmatized, but social comparisons turned out to be detrimental when the initial moral stigma was intense. Hence, rather than assuming that stigmacountering tactics are functional across different intensities of stigma, we should expect that they are relatively specific in their functioning to solve a particular adaptive stigmatization problem.

In addition, we contribute to theory by taking the effects of stigma management beyond the inward-facing challenges of individuals to outward-facing challenges in interactions with customers. This new perspective helps us to understand how an individual-level stigma can influence job performance of those who are the target of it. Therefore, our findings on how stigma affects frontline employees' job performance add to research on tasks that involve interpersonal interaction. Much of this research on employee-customer interactions has focused on emotional labor (e.g., Yagil \& Medler-Liraz, 2014; Wang, Singh, Li, Mishra, Ambrose, \& Biernat, 2017) or on frontline employees' intra-psychological identity dynamics (e.g., Ramarajan, Rothbard, \& Wilk, 2017) as determinants of job performance. Yet, when frontline employees are targets of a moral stigma, their role as organizational boundary spanners requires attempts to counter the stigma in interactions with customers, of which our work provides theoretical insights.

\section{Managerial Implications}

Our findings have implications for a number of practical issues in the management of customer-facing employees. First, we make theoretical claims about the relative instrumentality of two stigma-countering tactics for frontline employees' job performance and derive actionable implications. Such an understanding is managerially significant because the employment of 
stigma management requires cognitive and behavioral resources, resulting in the need to prioritize tactics (Neel, Neufeld, \& Neuberg, 2013). Our findings may open a door to ensuring that stigma-countering is instrumental for frontline employees' performance rather than acting as a constraint on their work outcomes.

In particular, our findings about the relative instrumentality of social proofing versus social comparisons will help frontline managers to specify more clearly the kinds of tactics that might be rewarded and help improve job performance of their morally tainted workers. Social proofing is a suitable means by which customer-facing employees can thwart a moral stigma, and managers may want to provide their employees with the necessary materials for successfully implementing social proofing. For example, results of customer satisfaction surveys, online reviews, or customer testimonials could be prepared in a professional way so that they could be handed to customers during frontline encounters. At the same time, our finding that social comparisons backfire and ultimately harm frontline workers' job performance is important for frontline supervisors. Their workers might intuitively seek to employ social comparisons in an attempt to overcome stigmatization. This is because downward social comparisons, when employed to inoculate the frontline worker's own self against stigma, can help to bolster occupational esteem (Ashforth et al., 2007).

\section{Limitations and Future Research}

In this study we focused on the interpersonal implications of stigma-countering tactics in business exchanges. However, as noted, stigma-countering may also have intrapersonal consequences, which can be both positive and negative for the individual stigma bearer. In terms of negative implications, for instance, previous work has shown that thwarting stigmas at the interpersonal level can come at the expense of negative intrapersonal outcomes, like emotional exhaustion (Singletary \& Hebl, 2009; Shelton, Richeson, \& Salvatore, 2005). Yet, in terms of 
positive intrapersonal outcomes, research on dirty work suggests that normalizing an occupational stigma can function as a coping mechanism that helps individuals to preserve or develop a positive self-image in spite of a tainted public image (Ashforth \& Kreiner, 2013, 1999; Ashforth et al., 2007). Therefore, research is needed to integrate both perspectives, which would enable scholars to intertwine intra and interpersonal outcomes of stigma-countering. In addition, Ashforth and Kreiner (2014) argue that members of tainted occupations are apt to experience paranoid social cognition, which can spur hypervigilance in interactions with others and lead them to infer affronts even if not intended (Ashforth \& Kreiner, 2014). Possibly, this hypervigilance triggers stigma-countering, when in fact the perceiver may not negatively stereotype the worker.

Furthermore, we have focused on studying a moral occupational stigma. Because people associate strong personal responsibility for category-membership (cf. Florey \& Harrison, 2000; Jones, Farina, Hastdorf, Markus, Miller, \& Scott, 1984), all occupational stigmas have been argued to carry at least some undertones of morality (Ashforth, 2019). We are hence optimistic that the mechanism and its boundary conditions that we have theorized in our study could be operating for occupational stigmas more generally. However, additional research is needed to test whether this is truly the case. Similarly, future scholars may also wish to examine whether the links theorized in this paper generalize to other occupations that carry a stigma in which job performance is at least partly dependent on the approval of external constituents; examples may include, but are not limited to, investment bankers, hedge fund managers, bill collectors, telemarketers, real estate agents, insurance agents, and even sex workers.

Our work also raises an intriguing question for the broader research on stigma management for stigmas originating from the actor's personal and social characteristics (e.g., 
Ali, Lyons, \& Ryan, 2017; Lyons et al., 2017; Davis, 1961; Johnson et al., 2014; Miller et al., 1995; Singletary \& Hebl, 2009). While there is the tentative notion in the literature that as with occupational stigmas, social comparisons play a role with demographic stigmas as well, there has been no empirical work that has yet directly explored this notion. For example, Lyons et al. (2018) argue that individuals in wheelchairs may say that they are not like other people in wheelchairs and have strengths in other areas - a downward social comparison. A similar tactic has been suggested to be used by people with hearing impairments (Lyons et al., 2017). Future scholars may wish to examine this idea more closely and might want to use a stereotype confirmation framework as well to derive their hypotheses.

Another interesting avenue would be to explore the triggers underlying the use of social comparisons. We speculate that stigmatized workers genuinely believe that they are better off than the reference group to which they compare their own group. Hence, they might assume that others come to see them as they see themselves (Kenny \& DePaulo, 1993). Central to this perspective is a false-consensus assumption — that is, people tend to assume substantial correspondence between their own perceptions and the perceptions of others (Frey \& Tropp, 2006). Future scholars may wish to explore whether such false consensus does indeed underlie the employment of social comparison claims.

We operationalized stigma-countering as an inclination to engage in stigma-countering tactics. From this perspective, frontline employees with a strong inclination to practice stigmacountering are more likely to engage in social proofing and social comparisons more frequently and more intensively. Our results suggest that such an inclination has implications for customers' negative occupational stereotypes as well as sales performance. However, because customers can influence frontline employees' behaviors and vice versa, future research might employ research 
designs that capture specific instances of social proofing and social comparisons at a dyadic level in order to flesh out reciprocal links between frontline employees' tactics and customers' responses (e.g., Walker, van Jaarsveld, \& Skarliki, 2016). For example, it may be interesting to study the particular verbal accounts customers might use that lead frontline workers to engage in either of the tactics more intensively.

While our cross-industry sample in Study 1 provides a middle ground for testing our hypotheses, within the sales occupation certain sales jobs might be more tainted than others. Consequently, the strength of the associations between negative stereotypes and the specific occupational subcategory might vary. The results from our experiment suggest that we should expect more pronounced effects of the countering tactics for sales occupations that are associated with particularly strong occupational stereotypes, because the stigma-countering tactics appeared to be of little diagnostic value for respondents in the low stigma intensity condition. However, more research is needed on how the tactics affect interpersonal outcomes in only mildly tainted jobs and on potential moderators to account for the idiosyncrasies of some occupations. One such moderator might be the status of the occupation or the task complexity. Ashforth and Kreiner (1999) speculate that occupational status, predicated on an occupation's rank relative to other occupations (cf. Devers et al., 2009), may reduce negative consequences of stigma. As such, investment bankers might be affected less negatively than retail bankers or insurance agents by their moral occupational stigma. At the same time, however, occupational status might entice occupational members to engage in downward social comparisons, which, in turn, may instigate more negative responses from external constituents. Accordingly, future scholars may wish to examine the implications of status for dirty work more closely. 
Finally, the stigma-countering tactics studied here are not exhaustive. For instance, in line with conceptual research on dirty work (Ashforth \& Kreiner, 1999), we focus on collectivistic countering tactics that conceptually address the group level, as opposed to the individual level of stigmatization, e.g., 'we here at this car dealership' vs. 'I am an individual salesperson at this car dealership' (see Tajfel \& Turner, 1979: p. 19). More research is needed to examine which occupational contexts promote which types of stigma-countering responses. For example, in work contexts with high task interdependence, individuals may have much to gain from collective responses to stigmatization (e.g., Kreiner et al., 2006). Similarly, the extent to which pay is linked to individual versus collective performance may impact which type of response is instigated.

\section{CONCLUSION}

As long as society brands some frontline occupations with a moral stigma, attempts by workers in these occupations to counter the stigma appear to be a functional response. Yet, in reality, this response can be dysfunctional, reinforcing others' negative stereotypes of immorality. This paper sheds light on the effectiveness of that response, which can help those with a moral occupational stigma mitigate stereotypes to enhance their job performance.

\section{REFERENCES}

Adams, J. 1976. The structure and dynamics of behavior in organizational boundary role. In M. D. Dunnette (Ed.), Handbook of industrial and organizational psychology: 1175-1199. Chicago, IL: Rand McNally College Pub. Co.

Adkins, R. T., \& Swan, J. E. 1981. Improving the public acceptance of sales people through professionalization. Journal of Personal Selling and Sales Management, 2: 32-38.

Ahearne, M., Bhattacharya, C. B., \& Gruen, T. 2005. Antecedents and consequences of customer-company identification: Expanding the role of relationship marketing. Journal of Applied Psychology, 90: 574-585.

Ahearne, M., Jelinek, R., \& Jones, E. 2007. Examining the effect of salesperson service behavior in a competitive context. Journal of the Academy of Marketing Science, 35: 603-616.

Alavi, S. Habel, J., Schmitz, C., Richter, B., \& Wieseke, J. 2018. The risky side of inspirational appeals in personal selling: when do customers infer ulterior salesperson motives? Journal of Personal Selling \& Sales Management, 38: 323-343. 
Ali, A. A., Lyons, B. J., \& Ryan, A. M. 2017. Managing a perilous stigma: Ex-offenders' use of reparative impression management tactics in hiring contexts. Journal of Applied Psychology, 102: 1271-1285.

Ashforth, B. E. 2019. Stigma and legitimacy: Two ends of a single continuum or different continua altogether? Journal of Management Inquiry, 28: 22-30.

Ashforth, B. E., \& Kreiner, G. E. 1999. "How can you do it?": Dirty work and the challenge of constructing a positive identity. Academy of Management Review, 24: 413-434.

Ashforth, B. E., \& Kreiner, G. E. 2013. Profane or profound? Finding meaning in dirty work. In J. D. Bryan, Z. S. Byrne, and M. F. Steger (Eds.), Purpose and meaning in the workplace: 127-150. Washington, D.C.: American Psychological Association.

Ashforth, B. E., \& Kreiner, G. E. 2014. Contextualizing dirty work: The neglected role of cultural, historical, and demographic context. Management and Organization Review, 10: 81-108.

Ashforth, B. E., Kreiner, G. E., Clark, M. A., \& Fugate, M. 2007. Normalizing dirty work: Managerial tactics for countering occupational taint. Academy of Management Journal, 50: 149-174.

Bagozzi, R. P, \& Yi, Y. 1988. On the evaluation of structural equation models. Journal of the Academy of Marketing Science, 16: 74-94.

Baldwin, M. 1992. Hero as salesman; salesman as hero: The heroic art of representation. Journal of Popular Culture, 26: 121-132.

Batt, R. 2002. Managing customer services: Human resource practices, quit rates, and sales growth. Academy of Management Journal, 45: 587-597.

Bateson, J., \& Hui, M.E. (1992). The ecological validity of photographic slides and videotapes in simulating the service setting. Journal of Consumer Research, 19: 271-281.

Bell, S. J., Auh, S., \& Smalley, K. 2005. Customer relationship dynamics: service quality and customer loyalty in the context of varying levels of customer expertise and switching costs. Journal of the Academy of Marketing Science, 33: 169-183.

Bergman, M. E., \& Chalkley, K. M. 2007. "Ex" marks a spot: The stickiness of dirty work and other removed stigmas. Journal of Occupational Health Psychology, 12: 251-265.

Bliese, P. D. 2000. Within-group agreement, non-independence, and reliability: Implications for data aggregation and analysis. In K. J. Klein and S. W. J. Kozlowski (Eds.), Multilevel theory, research, and methods in organizations: Foundations, extensions, and new directions: 349-381. San Francisco, CA: Jossey-Bass.

Bodenhausen, G. V. 1988. Stereotypic biases in social decision making and memory: Testing process models of stereotype use. Journal of Personality and Social Psychology, 55: 726737.

Bosmans, K., Mousaid, S., De Cuyper, N., Hardonk, S., Louckx, F., \& Vanroelen, C. 2016. Dirty work, dirty worker? Stigmatisation and coping strategies among domestic workers. Journal of Vocational Behavior, 92: 54-67.

Bunderson, J. S., \& Thompson, J. A. 2009. The call of the wild: Zookeepers, callings, and the double-edged sword of deeply meaningful work. Administrative Science Quarterly, 54: 3257.

Busch, P., \& Wilson, D. T. 1976. An experimental analysis of a salesman's expert and referent bases of social power in the buyer-seller dyad. Journal of Marketing Research, 13: 3-11.

Chebat, J. C., \& Kollias, P. 2000. The impact of empowerment on customer contact employees' roles in service organizations. Journal of Service Research, 3: 66-81. 
Cialdini, R. B., \& Goldstein, N. J. 2004. Social influence: Compliance and conformity. Annual Review of Psychology, 55: 591-621.

Cohen, G. L. 2003. Party over policy: The dominating impact of group influence on political beliefs. Journal of Personality and Social Psychology, 85: 808-822.

Cravens, D. W., Ingram, T. N., LaForge, R. W., \& Young, C. 1993. Behavior-based and outcome-based salesforce control systems. Journal of Marketing, 57(4): 47-59.

Crocker, J., \& Major, B. 1989. Social stigma and self-esteem: The self-protective properties of stigma. Psychological Review, 96: 608-630.

Crocker, J., Major, B., \& Steele, C. 1998. Social stigma. In D. T. Gilbert, S. T. Fiske, and G. Lindzey (Eds.), The handbook of social psychology, 4th ed., Vol.2: 504-553. New York, NY: McGraw-Hill.

Darley, J. M., \& Gross, P. H. 1983. A hypothesis-confirming bias in labeling effects. Journal of Personality and Social Psychology, 44: 20-33.

Davis, F. 1961. Deviance disavowal: The management of strained inter- action by the visibly handicapped. Social Problems, 9: 120-132.

Devers, C. E., Dewett, T., Mishina, Y., \& Belsito, C. A. 2009. A general theory of organizational stigma. Organization Science, 20: 154-171.

Dick, P. 2005. Dirty work designations: How police officers account for their use of coercive force. Human Relations, 58: 1363-1390.

Doney, P. M., \& Cannon, J. P. 1997. An examination of the nature of trust in buyer-seller relationships. Journal of Marketing, 61(2), 35-51.

Dovidio, J. F. 2001. On the nature of contemporary prejudice: The third wave. Journal of Social Issues, 57: 829-849.

Duncan, B. L. 1976. Differential social perception and attribution of intergroup violence: Testing the lower limits of stereotyping of Blacks. Journal of Personality and Social Psychology, 34: 590-598.

Fiske, S. T. 1998. Stereotyping, prejudice, and discrimination. In D. T. Gilbert, S. T. Fiske, \& G. Lindzey (Eds.), Handbook of Social Psychology, 4th ed.: 357-411. Boston: McGraw-Hill.

Fiske, S. T., \& Neuberg, S. L. 1990. A continuum of impression formation, from category-based to individuating processes: Influences of information and motivation on attention and interpretation. Advances in Experimental Social Psychology, 23: 1-74.

Fiske, S. T., \& Ruscher, J. B. 1993. Negative interdependence and prejudice: Whence the affect. In D. M. Mackie, \& D. L. Hamilton (Eds.), Affect, cognition, and stereotyping: Interactive processes in group perception: 239-268. San Diego, CA: Acadamic Press.

Fiske, S. T., Cuddy, A. J. C., Glick, P., \& Xu, J. 2002. A model of (often mixed) stereotype content: Competence and warmth respectively follow from perceived status and competition. Journal of Personality and Social Psychology, 82: 878-902.

Fiske, S. T., Neuberg, S. L., Beattie, A. E., \& Milberg, S. J. 1987. Category-based and attributebased reactions to others: Some informational conditions of stereotyping and individuating processes. Journal of Experimental Social Psychology, 23(5): 399-427.

Fiske, S. T., Xu, J., Cuddy, A. J. C., \& Glick, P. 1999. (Dis)respecting versus (dis)liking: Status and interdependence predict ambivalent stereotypes of competence and warmth. Journal of Social Issues, 55: 473-489.

Florey, A. T., \& Harrison, D. A. 2000. Responses to informal accommodation requests from employees with disabilities: Multistudy evidence on willingness to comply. Academy of Management Journal, 43: 224-233. 
Fornell, C., \& Larcker, D. F. 1981. Evaluating structural equation models with unobservable variables and measurement error. Journal of Marketing Research, 18: 39-50.

Frey, F. E., \& Tropp, L. R. 2006. Being seen as individuals versus as group members: Extending research on metaperception to intergroup contexts. Personality and Social Psychology Review, 10: 265-280.

Fyock, J., \& Stangor, C. 1994. The role of memory biases in stereotype maintenance: British Journal of Social Psychology, 33: 331-343.

Goffman, E. 1963. Stigma: Notes on the management of spoiled identity. Englewood Cliffs, NJ: Prentice Hall.

Goldstein, N. J., Cialdini, R. B., \& Griskevicius, V. 2008. A room with a viewpoint: Using social norms to motivate environmental conservation in hotels. Journal of Consumer Research, 35: 472-482.

Grandy, G. 2008. Managing spoiled identities: dirty workers' struggles for a favourable sense of self. Qualitative Research in Organizations and Management: An International Journal, 3: 176-198.

Grewal, D., Monroe, K.B., \& Krishnan, R. 1998. The effects of price-comparison advertising and buyers' perceptions of acquisition value, transaction value, and behavioral intentions. Journal of Marketing, 62(2): 46-59.

Hamilton, P., Redman, T., \& McMurray, R. 2019. 'Lower than a snake's belly': Discursive constructions of dignity and heroism in low-status garbage work. Journal of Business Ethics, 156: 889-901.

Hamilton, D. L., Sherman, S. J., \& Ruvolo, C. M. 1990. Stereotype-based expectancies: Effects on information processing and social behaviour. Journal of Social Issues, 46: 35-60.

Hamilton, D. L., \& Trolier, T. K. 1986. Stereotypes and stereotyping: An overview of the cognitive approach. In J. F. Dovidio and S. L. Gaertner (Eds.), Prejudice, discrimination, and racism: 127-163. San Diego, CA: Academic Press.

Hartman, K. B. 2006. Television and movie representations of salespeople: Beyond Willi Loman. Journal of Personal Selling and Sales Management, 26: 283-292.

Hilton, J. L., \& von Hippel, W. 1996. Stereotypes. Annual Review of Psychology, 47: 237-271.

Homburg, C., Müller, M., \& Klarmann, M. 2011. When should the customer really be king? On the optimum level of salesperson customer orientation in sales encounters. Journal of Marketing, 75(2): 55-74.

Hoorens, V., Pandelaere, M., Oldersma, F., \& Sedikides, C. 2012. The hubris hypothesis: You can self-enhance, but you'd better not show it. Journal of Personality, 80: 1237-1274.

Hox, J. J. 2010. Multilevel analysis. Techniques and applications. New York, NY: Routledge.

Hughes, E. C. 1951. Work and the self. In J. H. Rohrer \& M. Sherif (Eds.), Social psychology at the crossroads: 313-323. New York, NY: Harper and Brothers.

Hughes, J., Simpson, R., Slutskaya, N., Simpson, A., \& Hughes, K. 2016. Beyond the symbolic: a relational approach to dirty work through a study of refuse collectors and street cleaners. Work, Employment and Society, 31: 106-122.

Ingram, T. N., \& Schwepker, Jr., C. H. 1993. Perceptions of salespeople: Implications for sales managers and sales trainers. Journal of Marketing Management, 2(2): 1-8.

Jaworski, B. J., \& Kohli A. K. 1993. Market orientation: antecedents and consequences. Journal of Marketing, 57(3): 53-70.

Johnson, S. K., Sitzmann, T., \& Nguyen, A. T. 2014. Don't hate me because I'm beautiful: Acknowledging appearance mitigates the "beauty is beastly" effect. Organizational 
Behavior and Human Decision Processes, 125(2): 184-192.

Jones, E. E., Farina, A., Hastdorf, A., Markus, H., Miller, D., \& Scott, R. 1984. Social stigma: The psychology of marked relationships. New York: Freeman.

Jones, K. P., \& King, E. B. 2014. Managing concealable stigmas at work: A review and multilevel model. Journal of Management, 40: 1466-1494.

Kenny, D. A., \& DePaulo, B. M. 1993. Do people know how others view them? An empirical and theoretical account. Psychological Bulletin, 114: 145-161.

King, E. B., Shapiro, J. R., Hebl, M. R., Singletary, S. L., \& Turner, S. 2006. The stigma of obesity in customer service: A mechanism for remediation and bottom-line consequences of interpersonal discrimination. Journal of Applied Psychology, 91(3): 579-593.

Kleck, R. 1969. Physical stigma and task oriented interactions. Human Relations, 22: 53-60.

Kreft, I. G. G., de Leeuw, J., \& Aiken, L. S. 1995. The effect of different forms of centering in hierarchical linear models. Multivariate Behavioral Research, 30: 1-21.

Kreiner, G. E., Ashforth, B. E., \& Sluss, D. M. 2006. Identity dynamics in occupational dirty work: Integrating social identity and system justification perspectives. Organization Science, 17: 619-636.

Kreiner, G. E., \& Mihelcic, C. A. 2020. Stigmatized identities in organizations. In A. D. Brown (Ed.), The Oxford Handbook of Identities in Organizations. Oxford, U.K.: Oxford University Press.

Krieglmeyer, R., \& Sherman, J. W. 2012. Disentangling stereotype activation and stereotype application in the stereotype misperception task. Journal of Personality and Social Psychology, 103: 205-224.

Latane, B., \& Darley, J. M. 1967. Group inhibition of bystander intervention in emergencies, Journal of Personality and Social Psychology, 10: 215-221.

Leach, C. W., Ellemers, N., \& Barreto, M. 2007. Group virtue: the importance of morality (vs. competence and sociability) in the positive evaluation of in-groups. Journal of Personality and Social Psychology, 93: 234-249.

Lyons, B. J., Volpone, S. D., Wessel, J. L., \& Alonso, N. M. 2017. Disclosing a disability: Do strategy type and onset controllability make a difference? Journal of Applied Psychology, 102: 1375-1383.

Lyons, B. J., Martinez, L. R., Ruggs, E. N., Hebl, M. R., Ryan, A. M., O’Brien, K. R., \& Roebuck, A. 2018. To say or not to say: Different strategies of acknowledging a visible disability. Journal of Management, 44: 1980-2007.

MacKinnon, D. P., Lockwood, C. M., \& Williams, J. 2004. Confidence limits for the indirect effect: Distribution of the product and resampling methods. Multivariate Behavioral Research, 39: 99-128.

Macrae, C. N., \& Bodenhausen, G. V. 2000. Social cognition: Thinking categorically about others. Annual Review of Psychology, 51: 93-120.

Macrae, C. N., Stangor, C., \& Milne, A. B. 1994. Activating social stereotypes: A functional analysis. Journal of Experimental Social Psychology, 30(4): 370-389.

Mandrik, C. A., \& Bao, Y. 2005. Exploring the concept and measurement of general risk aversion. Advances in Consumer Research, 32: 531-539.

Marsh, H. W. 1996. Positive and negative global self-esteem: A substantively meaningful distinction or artifactors? Journal of Personality and Social Psychology, 70: 810-8719.

Mavin, S., \& Grandy, G., 2013. Doing gender well and differently in dirty work: The case of exotic dancing. Gender, Work \& Organization, 20: 232-251. 
McFarland, R. G., Challagalla, G. N., \& Shervani, T. A. 2006. Influence tactics for effective adaptive selling. Journal of Marketing, 70(4): 103-117.

Miller, C. T., Rothblum, E. D., Felicio, D., \& Brand, P. 1995. Compensating for stigma: Obese and nonobese women's reactions to being visible. Personality and Social Psychology Bulletin, 21: 1093-1106.

Mishina, Y., \& Devers, C. 2012. On being bad: Why a stigma is not the same as a bad reputation. In M. L. Barnett \& T. G. Pollock (Eds.), Oxford handbook of corporate reputation. Oxford, U.K.: Oxford University Press.

Muthén, L. K., \& Muthén, B. O. 1998-2017. Mplus user's guide (8th ed.). Los Angeles, CA: Muthén and Muthén.

Neel, R., Neufeld, S. L., \& Neuberg, S. L. 2013. Would an obese person whistle Vivaldi? Targets of prejudice self-present to minimize appearance of specific threats. Psychological Science, 24: 678-687.

Nickerson, R. S. 1998. Confirmation bias: A ubiquitous phenomenon in many guises. Review of General Psychology, 2(2): 175-220.

Nunnally, J. C. 1978. Psychometric theory (2nd ed.). New York, NY: McGraw-Hill.

Pettigrew, T. F., Christ, O., Wagner, U., \& Stellmacher, J. 2007. Direct and indirect intergroup contact effects on prejudice: A normative interpretation. International Journal of Intercultural Relations, 31: 411-425.

Preacher, K. J., Rucker, D. D., \& Hayes, A. F. 2007. Addressing moderated mediation hypotheses: Theory, methods, and prescriptions. Multivariate Behavioral Research, 42: 185-227.

Ramarajan, L., Rothbard, N. P., \& Wilk, S. L. 2017. Discordant vs. harmonious selves: The effects of identity conflict and enhancement on sales performance in employee-customer interactions. Academy of Management Journal, 60: 2208-2238.

Raudenbush, S. W., \& Bryk, A. S. 2002. Hierarchical linear models: Applications and data analysis methods. Newbury Park, CA: Sage.

Reynolds, K. E., \& Beatty, S. E. 1999. Customer benefits and company consequences of customer-salesperson relationships in retailing. Journal of Retailing, 75: 11-32.

Rotter, J. B., \& Stein, D. K. 1971. Public attitudes toward the trustworthiness, competence, and altruism of twenty selected occupations. Journal of Applied Social Psychology, 1: 334-343.

Sagar, H. A., \& Schofield, J. W. 1980. Racial and behavioral cues in black and white children's perceptions of ambiguously aggressive acts. Journal of Personality and Social Psychology, 39: 590-598.

Savary, J., Goldsmith, K., \& Dhar, R. 2015. Giving against the odds: When tempting alternatives increase willingness to donate. Journal of Marketing Research, 52: 27-38.

Saxe, R., \& Weitz, B. A. 1982. The SOCO scale: A measure of the customer orientation of salespeople. Journal of Marketing Research, 19: 343-351.

Schmitt, D. P., \& Allik, J. 2005. Simultaneous administration of the Rosenberg self-esteem scale in 53 nations: Exploring the universal and culture-specific features of global self-esteem. Journal of Personality and Social Psychology, 89: 623-642.

Shelton, J. N., Richeson, J. A., \& Salvatore, J. 2005. Expecting to be the target of prejudice: Implications for interethnic interactions. Personality and Social Psychology Bulletin, 31: 1189-1202.

Shrout, P. E., \& Bolger, N. 2002. Mediation in experimental and nonexperimental studies: New procedures and recommendations. Psychological Methods, 7: 422-445. 
Singletary, S. L., \& Hebl, M. R. 2009. Compensatory strategies for reducing interpersonal discrimination: The effectiveness of acknowledgments, increased positivity, and individuating information. Journal of Applied Psychology, 94: 797-805.

Slutskaya, N., Simpson, R., Hughes, J., Simpson, A., \& Uygur, S. 2016. Masculinity and class in the context of dirty work. Gender, Work \& Organization, 23: 165-182.

Snijders, T., \& Bosker, R. 1999. Multilevel modeling: An introduction to basic and advanced multilevel modeling. London: Sage Publishers.

Sridhar, S., \& Srinivasan, R. 2012. Social influence effects in online product ratings. Journal of Marketing, 76(5): 70-88.

Stacey C. 2006. Finding dignity in dirty work: the constraints and rewards of low-wage home care labour. Sociology of Health and Illness, 27: 831-854.

Stangor, C., \& Crandall, C. S. 2000. Threat and the social construction of stigma. In T. F. Heatherton, R. E. Kleck, M. R. Hebl, \& J. G. Hull (Eds.), The social psychology of stigma: 62-87. New York, NY: Guilford.

Sujan, M., Bettman, J. R., \& Sujan, H. 1986. Effects of consumer expectations on information processing in selling encounters. Journal of Marketing Research, 23: 346-353.

Tajfel, H., \& Turner, J. C. 1979. The social identity theory of intergroup behavior. In S. Worchel, \& W. G. Austin (Eds.), Psychology of Intergroup Relations: 33-47. Chicago, IL: NelsonHall.

Thomas, R. W., Soutar, G. N., \& Ryan, M. M. 2001. The selling orientation-customer orientation (SOCO) scale: A proposed short form. Journal of Personal Selling and Sales Management, 21: 63-69.

Tracy, S. J., \& Scott, C. 2006. Sexuality, masculinity, and taint management among firefighters and correctional officers: Getting down and dirty with "America's heroes" and the "scum of law enforcement." Management Communication Quarterly, 20: 6-38.

Van Damme, C., Hoorens, V., \& Sedikides, C. 2016. Why self-enhancement provokes dislike: The hubris hypothesis and the aversiveness of explicit self-superiority claims. Self and Identity, 15: 173-190.

Walker, D. D., Van Jaarsveld, D. D., \& Skarlicki, D. P. 2017. Sticks and stones can break my bones but words can also hurt me: The relationship between customer verbal aggression and employee incivility. Journal of Applied Psychology, 102: 163-179.

Wang, Z., Singh, S. H., Li, Y. J., Mishra, S., Ambrose, M., \& Biernat, M. 2017. Effects of employee's positive affective displays on customer loyalty intentions: An Emotion-asSocial-Information Perspective. The Academy of Management Journal, 60: 109-129.

Welch, E. 2005. Shopping in the Renaissance: Consumer cultures in Italy 1400-1600. New Haven, CT: Yale University Press.

Word, C. O., Zanna, M. P., \& Cooper, J. 1974. The nonverbal mediation of self-fulfilling prophecies in interracial interaction. Journal of Experimental Social Psychology, 10(2): 109-120.

Wojciszke, B., Bazinska, R., \& Jaworski, M. 1998. On the dominance of moral categories in impression formation. Personality and Social Psychological Bulletin, 24: 1245-1257.

Yagil, D., \& Medler-Liraz, H. 2014. Moments of truth: Examining transient authenticity and identity in service encounters. Academy of Management Journal, 56: 473-497. 
TABLE 1 Study 1: Means, Standard Deviations, and Bivariate Correlations

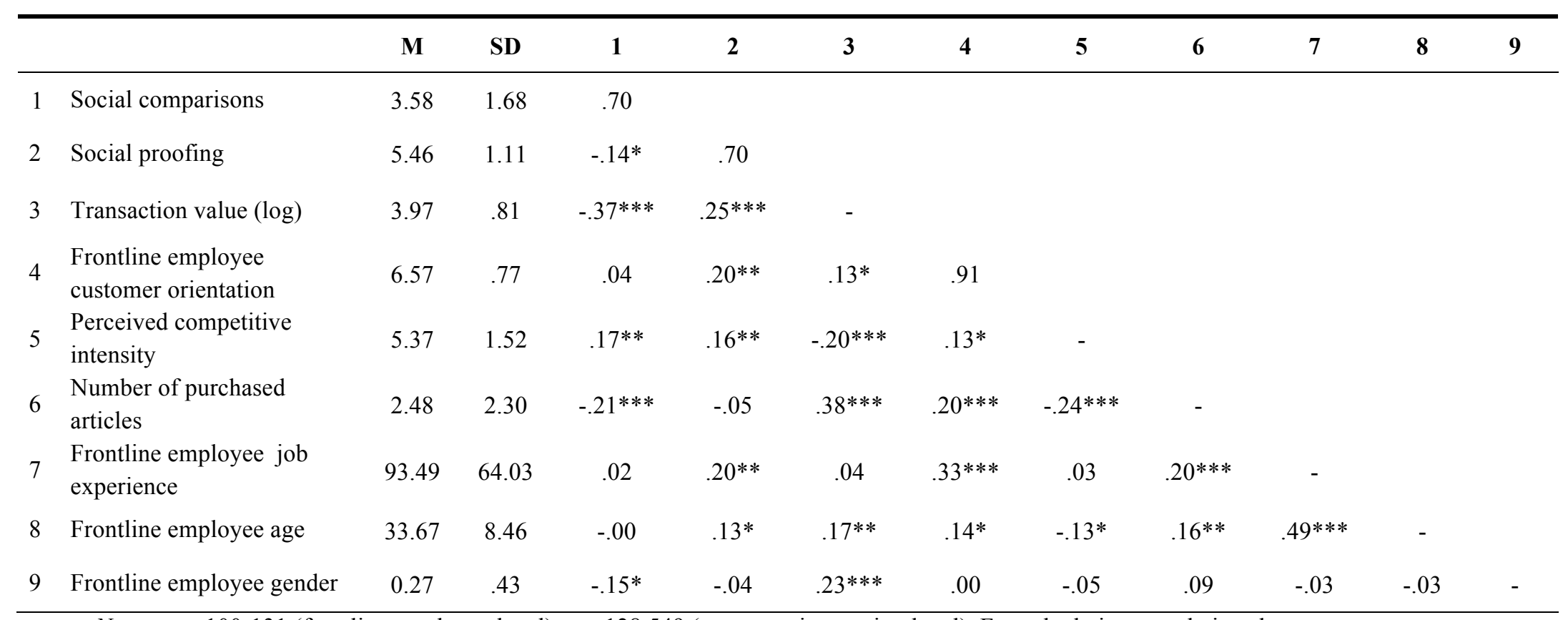

Notes: $\mathrm{n}=100-131$ (frontline employee level), $\mathrm{n}=128,549$ (customer-interaction level). For calculating correlations between constructs at different levels of analysis, data were aggregated at the frontline employee level. Correlations should be interpreted with caution because they are not adjusted for non-independence. Figures on the diagonals are scale reliabilities (Cronbach's alpha). Salesperson gender: female $=$ ' 0 '; male $=$ ' 1 '.

$* * * p<.01 ; * * p<.05 ; * p<.10$ (two-tailed). 


\section{TABLE 2 Study 1: Estimated Path Coefficients}

\begin{tabular}{lc}
\hline \multicolumn{1}{c}{$\begin{array}{c}\text { Dependent Variable: Transaction Value per Customer } \\
\text { Transaction (log) }\end{array}$} & Estimates (SE) \\
\hline $\begin{array}{l}\text { Main effects } \\
\text { Social comparisons }\end{array}$ & $-.034(.008)^{* * *}$ \\
Social proofing & $.027(.012)^{* *}$ \\
& \\
Control variables & $.029(.014)^{* *}$ \\
Frontline employee customer & $-.018(.013)$ \\
orientation & $.147(.003)^{* * *}$ \\
Perceived competitive intensity & $.001(.000)$ \\
Number of purchased articles & $.003(.002)^{*}$ \\
Frontline employee job experience & $.102(.038)^{* * *}$ \\
Frontline employee age & Frontline employee gender \\
Notes: The table presents unstandardized path coefficients; standard \\
rrors are shown in parentheses. To control for the specific month in \\
which the transaction occurred, we included a dummy variable for \\
ach month (but not for January as reference month) in the model \\
stimations at the within-level. \\
$* * * p<.01 ; * * p<.05 ; *<<$ (two-tailed).
\end{tabular}


TABLE 3 Study 2: Means, Standard Deviations, and Bivariate Correlations

\begin{tabular}{|c|c|c|c|c|c|c|c|c|c|c|c|c|c|c|c|c|}
\hline & & M & SD & 1 & 2 & 3 & 4 & 5 & 6 & 7 & 8 & 9 & 10 & 11 & 12 & 13 \\
\hline 1 & Social comparisons & 3.20 & 1.55 & .72 & & & & & & & & & & & & \\
\hline 2 & Social proofing & 4.92 & 1.41 & $.20 * * *$ & .70 & & & & & & & & & & & \\
\hline 3 & Salesperson's age & 37.36 & 11.25 & .12 & -.03 & - & & & & & & & & & & \\
\hline 4 & $\begin{array}{l}\text { Customers' negative } \\
\text { occupational stereotypes }\end{array}$ & 3.51 & 1.49 & $.14 *$ & $-.13 *$ & -.02 & .90 & & & & & & & & & \\
\hline 5 & Customer age & 43.15 & 14.36 & .05 & -.01 & .07 & .07 & - & & & & & & & & \\
\hline 6 & $\begin{array}{l}\text { Customer category } \\
\text { experience }\end{array}$ & 8.26 & 26.46 & .11 & -.04 & .09 & -.04 & .07 & - & & & & & & & \\
\hline 7 & $\begin{array}{l}\text { Perceived sentiment of the } \\
\text { interaction }\end{array}$ & 6.01 & 1.22 & .04 & -.02 & .10 & $-.38 * * *$ & $.14 * * *$ & .07 & - & & & & & & \\
\hline 8 & $\begin{array}{l}\text { Perceived customer } \\
\text { orientation }\end{array}$ & 4.95 & 1.48 & .00 & .02 & .01 & $-.31 * * *$ & $.12 * * *$ & -.01 & $.50 * * *$ & .91 & & & & & \\
\hline 9 & Perceived quality & 5.38 & 1.33 & .09 & .10 & .07 & $-.18 * * *$ & .04 & .07 & $.28 * * *$ & $.21 * * *$ & - & & & & \\
\hline 10 & Job performance & 0.55 & .50 & -.05 & .04 & .04 & $-.16 * * *$ & $.16^{* * *}$ & .08 & $20 * * *$ & $.12 * * *$ & $.24 * * *$ & - & & & \\
\hline 11 & Relationship length & 42.65 & 31.38 & -.12 & -.12 & .02 & .04 & $.17 * * *$ & -.07 & .06 & $.16^{* *}$ & -.04 & $.21 * * *$ & - & & \\
\hline 12 & Customer gender & 0.61 & 0.49 & $-.16 * *$ & .01 & .08 & -.04 & .07 & .03 & -.00 & -.06 & .07 & -.02 & .01 & - & \\
\hline 13 & Customer risk aversion & 4.56 & 1.87 & .19 & .09 & .02 & .07 & $.16^{* *}$ & -.11 & .01 & .06 & -.12 & .04 & $.13 *$ & $-.12 *$ & - \\
\hline
\end{tabular}

Notes: The table shows the pairwise correlations. Correlations should be interpreted with caution because they are not adjusted for non-independence. For calculating correlations, constructs modeled at the frontline employee level were group-mean centered at the store level. For calculating correlations between variables at different levels of analysis, data were aggregated at the frontline employee level. Variables 1-3 were measured at the frontline employee level; variables 4-13 were measured at the customer level. Figures on the diagonals are scale reliabilities (Cronbach's alpha).

$n($ between $)=161-137 ; n$ (within) $=535-152 * * * p \leq .01 ; * * \leq .05 ; * p \leq .10$ (two-tailed);

Job performance is dummy-coded: ' 0 ' = no purchase, ' 1 ' = purchase; gender is dummy-coded: ' 0 ' $=$ female, ' 1 ' $=$ male; relationship length was recoded to months. 


\section{TABLE 4 Study 2: Estimated Path Coefficients}

Model

Main effects

Social comparisons

Social proofing

Occupational stereotypes of immorality $\rightarrow$ Occupational stereotypes of immorality

$\rightarrow$ Occupational stereotypes of immorality

$\rightarrow$ Job Performance
Estimates

$0.087(0.043)^{* *}$

$-0.082(0.040)^{* *}$

$-0.249(0.087)^{* * *}$

\section{Controls}

Perc. product quality

Perc. customer orientation

Customer age

Customer category experience

Customer gender

Customer risk aversion

Relationship length

Interaction sentiment

Frontline employee age $\rightarrow$ Job performance

$\rightarrow$ Job performance

$\rightarrow$ Occupational stereotypes of immorality

$\rightarrow$ Occupational stereotypes of immorality

$\rightarrow$ Occupational stereotypes of immorality

$\rightarrow$ Occupational stereotypes of immorality

$\rightarrow$ Occupational stereotypes of immorality

$\rightarrow$ Occupational stereotypes of immorality

$\rightarrow$ Occupational stereotypes of immorality
$0.400(0.098)^{* * *}$

$0.015(0.086)$

$0.008(0.005)$

$-0.002(0.002)$

$-0.075(0.126)$

$0.039(0.071)$

$0.001(0.004)$

$-0.521(0.051)^{* * *}$

$-0.003(0.006)$

Notes: $n$ (within level) $=535 ; n$ (between level $)=161$. The table presents unstandardized path coefficients; standard errors are shown in parentheses. Industry-fixed effects were included at the between level.

$* * * p<.01 ; * * p<.05 ; * p<.10$ (two-tailed).

We also ran a version of the model, in which we included an interaction effect between social proofing and social comparison claims on occupational stereotypes of immorality. Results show a significant interaction effect $(\mathrm{b}=0.048, \mathrm{SE}=0.017, p<.01)$ such that social comparisons attenuate the positive effect of social proofing on occupational stereotypes of immorality. Furthermore, we ran a model in which we additionally controlled for dealer reputation. In this model all hypothesized relationships remain stable. 
TABLE 5 Study 3: Means, Standard Deviations, and Bivariate Correlations

\begin{tabular}{|c|c|c|c|c|c|c|c|c|}
\hline & & $\mathbf{M}$ & SD & 1 & 2 & 3 & 4 & 5 \\
\hline 1 & Social comparison dummy & .33 & .47 & - & & & & \\
\hline 2 & Social proofing dummy & .34 & .47 & $-.49 * * *$ & - & & & \\
\hline 3 & $\begin{array}{l}\text { Customers' occupational } \\
\text { stereotypes of immorality }\end{array}$ & 3.99 & 1.05 & $.08^{* *}$ & $-.08 * *$ & $(.84)$ & & \\
\hline 4 & Purchase intention & 4.09 & 1.23 & $-.08 * *$ & .06 & $-.53 * * *$ & - & \\
\hline 5 & Frontline job dummy & .50 & .50 & -.00 & -.02 & .07 & -.05 & - \\
\hline
\end{tabular}

Notes: $\mathrm{n}=820 * * * p<.01, * * p<.05$ (two-tailed);

Social comparisons/social proofing coded as ' 1 ', control coded as ' 0 '; frontline job dummy: Job with strong moral stigma intensity coded as ' 1 ', job with low moral stigma intensity coded as ' 0 '. Figures on the diagonals are scale reliabilities (Cronbach’s alpha) 
TABLE 6 Study 3: Bootstrapped Conditional Indirect Effects of Stigma-Countering Tactics on Job Performance

\begin{tabular}{|c|c|c|c|c|c|c|c|c|}
\hline Hypotheses & $\begin{array}{c}\text { Independent } \\
\text { Variable / } \\
\text { Experimental } \\
\text { Factor }\end{array}$ & Mediator & $\begin{array}{c}\text { Level of } \\
\text { Moderator } \\
\text { Moral } \\
\text { Stigma } \\
\text { Intensity }\end{array}$ & $\begin{array}{l}\text { Direct } \\
\text { Effect }\end{array}$ & $\begin{array}{l}\text { Conditional } \\
\text { Indirect } \\
\text { Effect }\end{array}$ & $\begin{array}{c}\text { CI } \\
95 \% \\
\text { Lower } \\
\text { Bound }\end{array}$ & $\begin{array}{c}\text { CI } \\
95 \% \\
\text { Upper } \\
\text { Bound }\end{array}$ & $\begin{array}{c}\text { Type of } \\
\text { Mediation }\end{array}$ \\
\hline \multirow[t]{2}{*}{ H3b: } & Social Proofing & & High & & $.091^{++}$ & .028 & .154 & Full \\
\hline & Social Proofing & $\begin{array}{c}\text { Occupational } \\
\text { Stereotypes }\end{array}$ & Low & & $-.032^{\mathrm{ns}}$ & -.090 & .025 & - \\
\hline \multirow[t]{2}{*}{ H3a: } & Social Comparisons & $\begin{array}{c}\text { of } \\
\text { Immorality }\end{array}$ & High & & $-.075^{++}$ & -.131 & -.018 & Full \\
\hline & Social Comparisons & & Low & & $.022^{\mathrm{ns}}$ & -.032 & .077 & - \\
\hline & Social Comparisons & & High & $-.003^{\mathrm{ns}}$ & & -.103 & .097 & \\
\hline & Social Comparisons & & Low & $-.076^{\mathrm{ns}}$ & & -.164 & .012 & \\
\hline & Social Proofing & & High & $.026^{\mathrm{ns}}$ & & -.077 & .129 & \\
\hline & Social Proofing & & Low & $-.030^{\mathrm{ns}}$ & & -.120 & .060 & \\
\hline
\end{tabular}

Notes: Standardized coefficients are shown. ${ }^{++}$significant at the $95 \%$ confidence interval; ns = not significant (two-tailed); comparison/proofing coded as ' 1 ', control coded as ' 0 '; Frontline job dummy: Job with high moral stigma intensity coded as ' 1 ', job with low moral stigma intensity coded as ' 0 '. 
FIGURE 1a The Effects of Countering a Moral Occupational Stigma on Job Performance

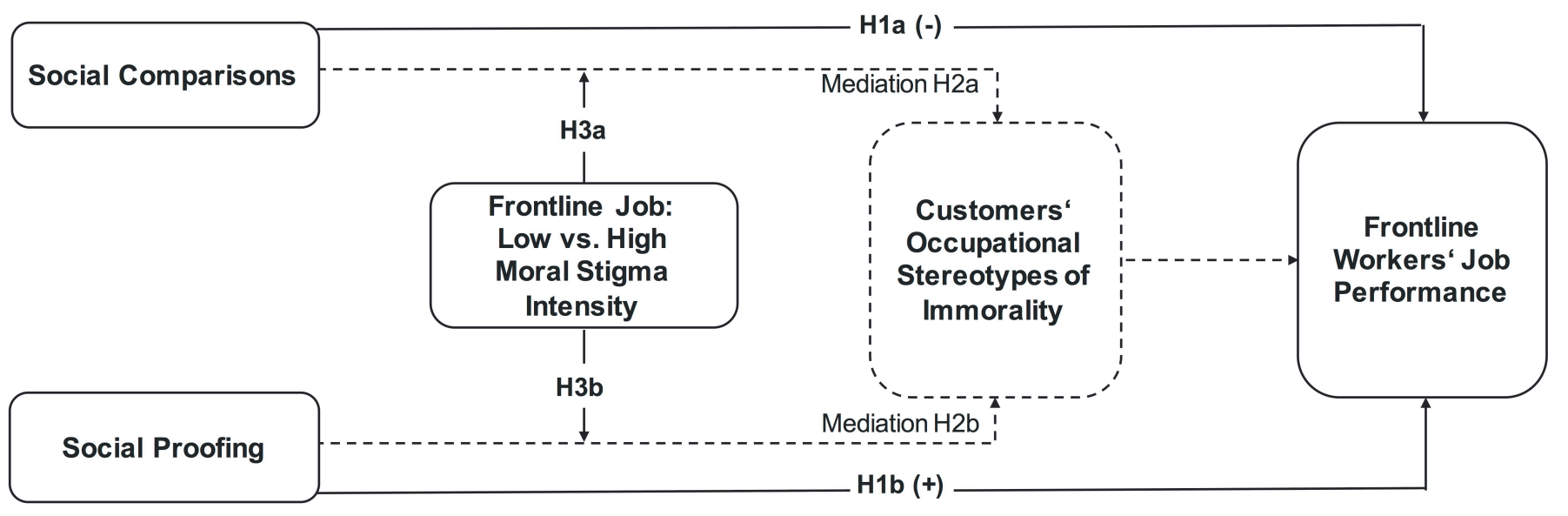

FIGURE 1b Study 3: Results Path Model

H3a:

Indirect effect social comparsons for frontline job with high moral stigma intensity $=\left(\beta_{2}{ }^{*} \beta_{5}\right)$

Indirect effect social comparisons for frontline job with low moral stigma intensity $=\left(\beta_{1}{ }^{*} \beta_{5}\right)$

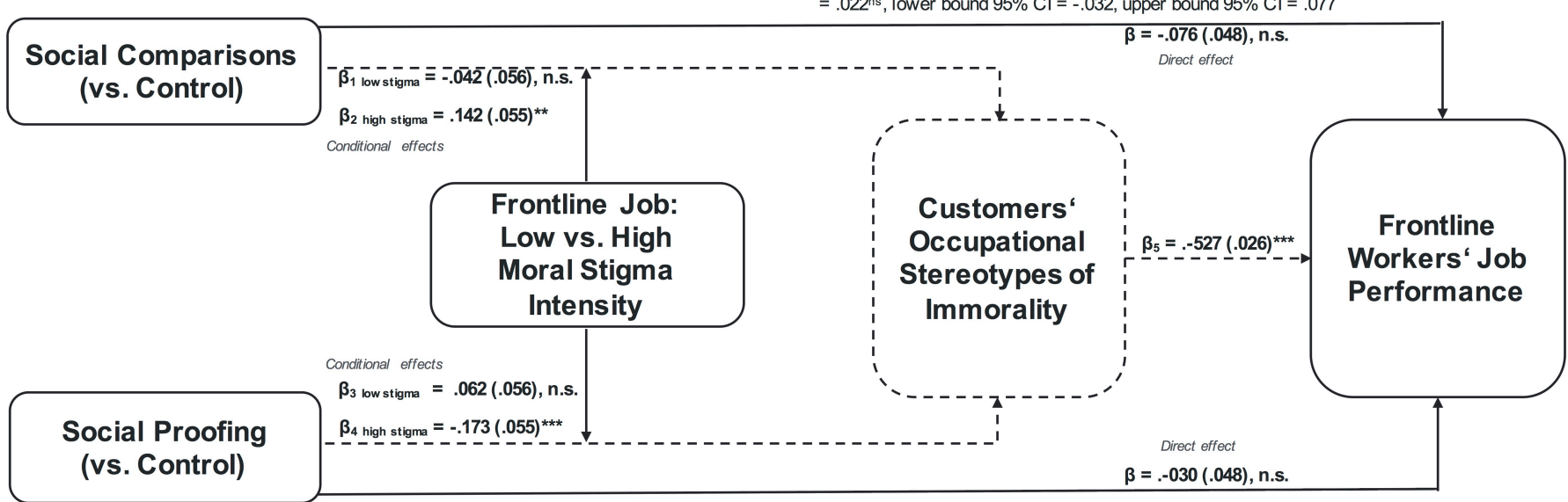

H3b: $\beta=.-030(.048), \mathrm{n} . \mathrm{s}$. $=.091$, lower bound $95 \% \mathrm{Cl}=.028$, upper bound $95 \% \mathrm{Cl}=.154$

Indirect effect social proofing for frontline job with low moral stigma intensity $=\left(\beta_{3}{ }^{*} \beta_{5}\right.$ 


\begin{tabular}{|c|c|c|}
\hline \multicolumn{3}{|c|}{$\begin{array}{c}\text { APPENDIX A } \\
\text { Measurement Scales for Key Constructs }\end{array}$} \\
\hline Construct & Items (Source) & Study \\
\hline $\begin{array}{l}\text { Customers' occupational } \\
\text { stereotypes of immorality } \\
\text { (reverse coded) }\end{array}$ & $\begin{array}{l}\text { 7-point scale: "totally disagree" to "totally agree" (following Fiske et al. 2002; 1999): } \\
\text { Salespeople are... } \\
\text { 1. ...trustworthy. } \\
\text { 2. ... sincere. } \\
\text { 3. ...good-natured. }\end{array}$ & Study 2 , and 3 \\
\hline Social proofing & $\begin{array}{l}\text { 7-point scale: "totally disagree" to "totally agree" (new scale): } \\
\text { If you feel that your customers harbor negative stereotypes toward you (e.g., "a } \\
\text { sleazy salesperson"), what do you do in order to rebut these stereotypes? } \\
\text { 1. I refer to the high degree of customer loyalty our branch enjoys. } \\
\text { 2. I point out that many of our customers are satisfied and were not tricked. } \\
\text { 3. I refer customers to third-party sources, such as other customers, test results, } \\
\text { etc. in order to counter the stereotypes. }\end{array}$ & Study 1,2 , and 3 \\
\hline Social comparisons & $\begin{array}{l}\text { 7-point scale: "totally disagree" to "totally agree" (new scale): } \\
\text { If you feel that your customers harbor negative stereotypes toward you (e.g., "a } \\
\text { sleazy salesperson"), what do you do in order to rebut these stereotypes? } \\
\text { 1. I point out that the stereotypes might apply to salespeople of other companies, } \\
\text { but not to our salespeople here. } \\
\text { 2. I admit that salespeople of other companies might be using dubious methods, } \\
\text { but I make clear that this is not the case with the salespeople of our branch here. } \\
\text { 3. During sales encounters, I dissociate from the larger group of salespeople. }\end{array}$ & Study 1,2 , and 3 \\
\hline $\begin{array}{l}\text { Transaction value per } \\
\text { salesperson-customer } \\
\text { transaction }\end{array}$ & Monetary amount purchased per transaction, archival company data & Study 1 \\
\hline Job Performance & $\begin{array}{l}\text { Dichotomous scale with the response options "Yes" and "No": } \\
\text { 1. Did you buy the product/service in question after the encounter? } \\
\text { 7-point scale: "very low" to "very high" (own operationalization): } \\
\text { 1. The likelihood that I would buy at this store is... }\end{array}$ & $\begin{array}{l}\text { Study } 2 \\
\text { Study } 3\end{array}$ \\
\hline
\end{tabular}

Sven Mikolon (s.mikolon@imperial.ac.uk) is an assistant professor of marketing at Imperial College Business School, Imperial College London. His research bridges the literature on organizational psychology with that on consumer behavior, with a strong focus on the customerfrontline worker-interface. This includes research on how social evaluations, expectations, and cognitive biases influence workers' job performance and customers' mind-set outcomes.

Sascha Alavi (sascha.alavi@ruhr-uni-bochum.de) is a professor of sales management at the Sales Management Department at the Ruhr-University of Bochum, Germany. His research interests center on sales and services marketing, and the employee-customer interface.

Anika Reynders (anika.reynders@rub.de) is an independent researcher. She received her doctoral degree from Ruhr-University of Bochum. Anika is currently responsible for sales partner development at an international company. Her research interests focus on personal selling and behavioral pricing. 